Preprints of the

Max Planck Institute for

Research on Collective Goods

Bonn 2006/14

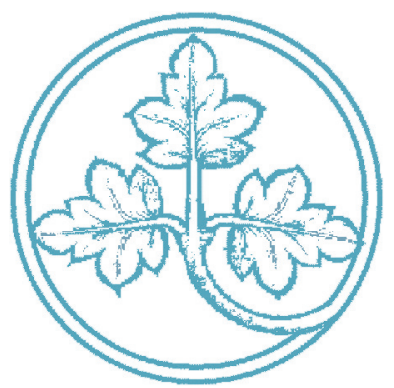

The herd moves?

Emergence and self-organization in collective actors

Martin Beckenkamp

This paper can be downloaded free of charge from the

Social Science Research Network at http://ssrn.com/abstract $=929091$

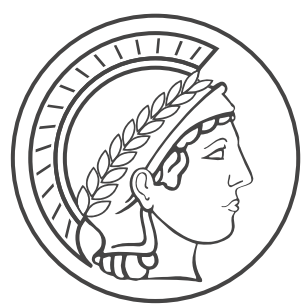




\title{
The herd moves? \\ Emergence and self-organization in collective actors
}

\author{
Martin Beckenkamp
}

July 2006 


\title{
The herd moves? Emergence and self-organization in collective actors ${ }^{1}$
}

\author{
Martin Beckenkamp
}

\section{Content}

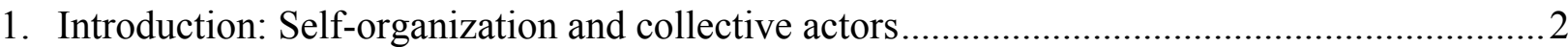

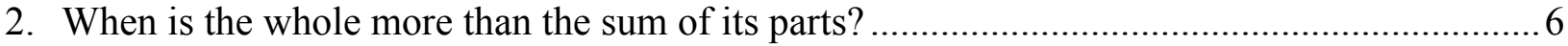

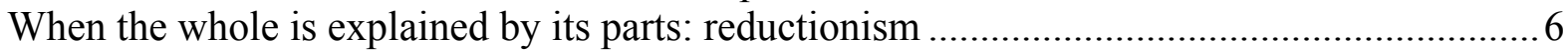

When the whole cannot be explained by its parts: about holism.............................................. 8

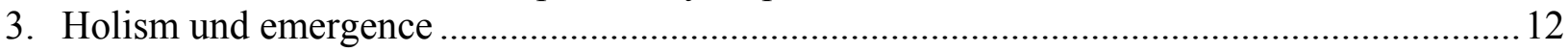

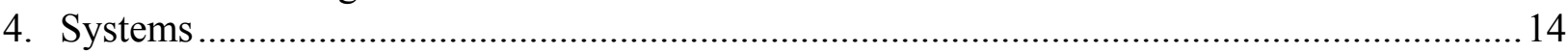

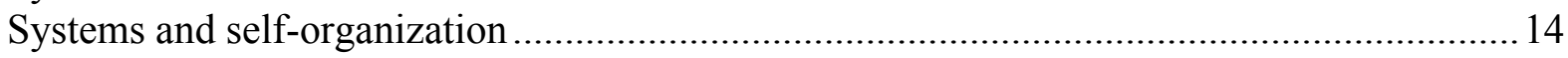

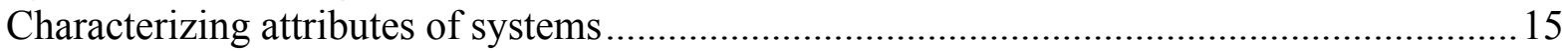

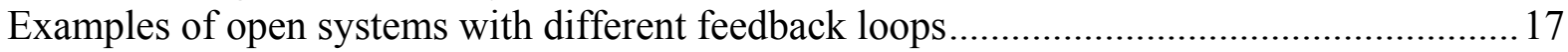

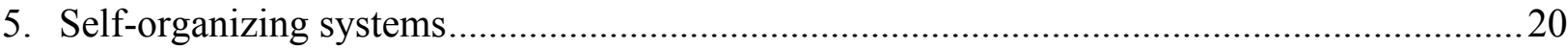

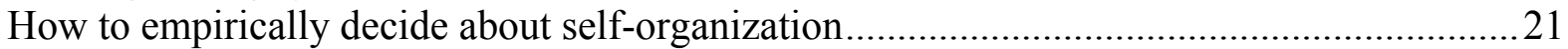

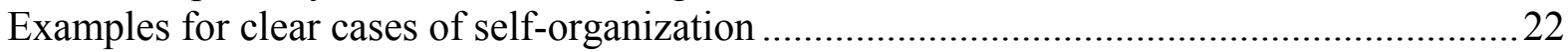

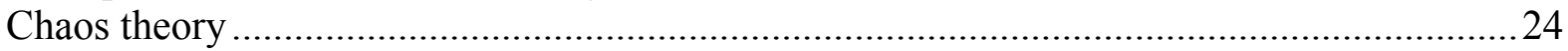

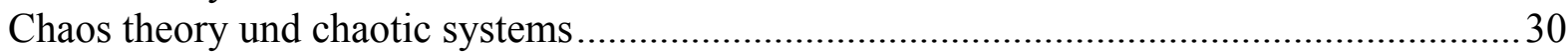

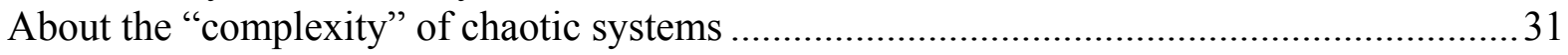

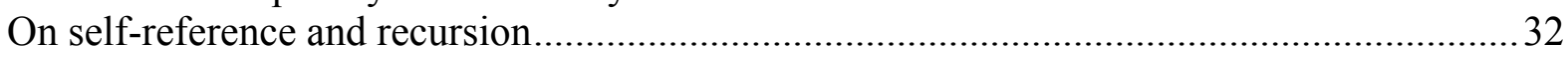

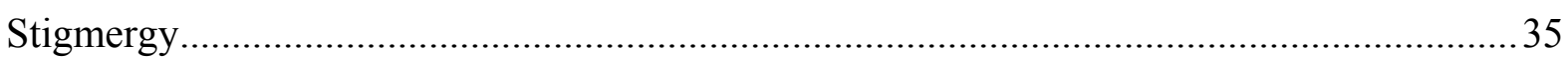

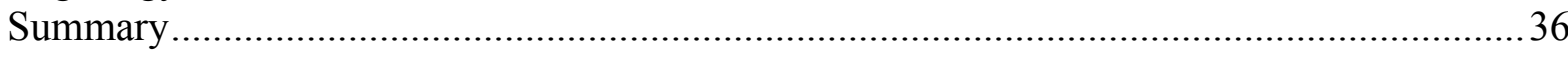

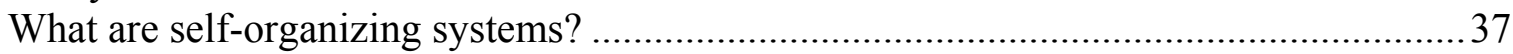

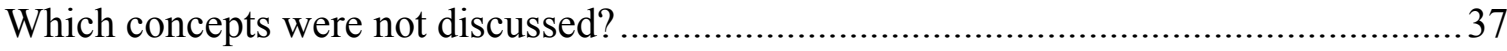

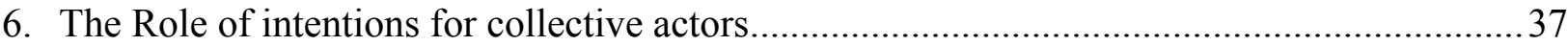

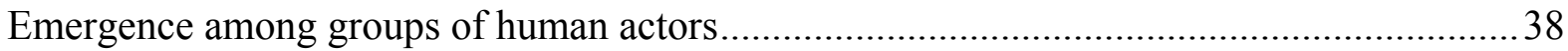

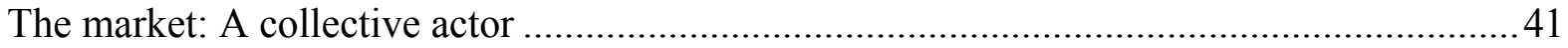

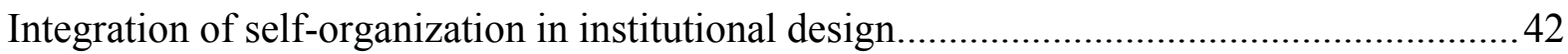

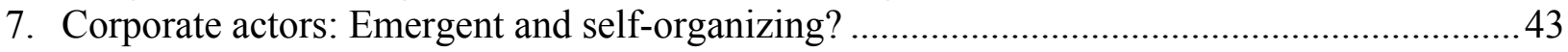

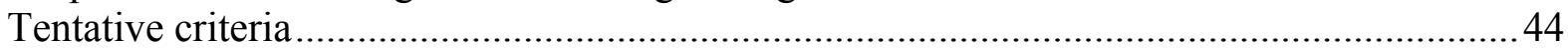

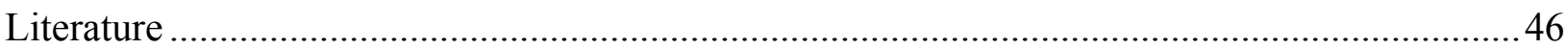

1 I'm very grateful to the corporate actor group of the Max Planck Institute for the Research on Collective Goods in Bonn. The considerations offered in this paper have been developed in the context of this group. The comments, suggestions and objections of Anne von Aaken, Boris Brandhoff, Christoph Engel, David Gerber, Heike Hennig-Schmidt, Alkuin Kölliker, Remi Maier-Rigaud, Axel Ostmann and Stephan Tontrup were extremely supportive. I also thank Elinor Ostrom, Hendrik Hakenes, as well as Michael Beckenkamp, for their helpful comments. Last but not least, again Darrell Arnold's linguistic assistance was tremendous, and I also am indebted to him for very useful remarks about the content. 


\section{Introduction: Self-organization and collective actors}

Headlines such as "Deutsche Bank plans to cut 6,400 jobs worldwide" can be read in the newspapers. Often, it is not clear whether the references to such expressions as the "Deutsche Bank" in such contexts are metaphors or whether they can be understood literally, so that in fact there is a decision of Deutsche Bank. Perhaps this decision was made individually by the CEO, Josef Ackermann, who can enforce it in the given strategic constellation? Or is this act also sustained if Ackermann is not (or no longer) the CEO? Can Deutsche Bank act? Or must all explanations finally refer to the actions of the individual actors, who are members of Deutsche Bank and are qualified to decide for the bank?

In this concrete form and with reference to the contextual significance, the question is hard to answer. Nevertheless it is a core issue of significance for all collective actors. It is about the question whether - and, if so, under which conditions - the behavior of collective actors emerges with behavioral qualities that cannot be explained by the attributes and relations of the elements constituting that whole. ${ }^{2}$ In this abstract form, this question concerns many different disciplines, and it can be broken down into several issues.

Which reasons can be given for the claim that new qualities can be identified in an integrated whole - a holon as Arthur Koestler (1969) tagged the term - that cannot be explained by its atomistic parts and their interrelations with each other? This issue will be treated in the following argument: If many parts of the holon are integrated in a multi-relation, i.e. a relation that integrates many parts and defines their structure, then the holon has a quality in its own and thus an explanatory value in its own; the whole is more than the sum of its respective parts. Besides collective actors, this argument is also relevant for corporate actors because, in corporations, actors are embedded in a multi-relational network, which becomes manifest in mutual responsibilities and mutual controls that clearly surpass dyadic relationships. Thus, in a certain sense, the individual actors are "forced" into their respective roles. Therefore, to turn to our example, the evaluation of explanations of the behavior of Deutsche Bank that are based on the actions of Josef Ackermann would include an appraisal of the leeway that Ackermann takes in changing the network and the interrelationships.

Besides this, additional criteria can be found if the system and the running processes are taken into consideration. Further skepticism about reductionist arguments is appropriate if it can be shown that the system is capable of self-organization. In this case, too, the behavior of Deutsche Bank can hardly be explained by merely referring to Josef Ackermann and some other important decision makers in that institution. This answer raises new questions that are handled in this paper: What exactly does self-organization mean and how we can decide whether a given system is self-organizing? It will be shown that mathematical chaos theory allows for conceptually and

2 Some of the arguments in the following sections get by without system-theoretic considerations. Therefore, the formulation makes sense. However, within a system-theoretic view, as described by Luhmann, this sentence would miscconceive central concepts, because the elements of such systems have no substantial character sui generis. I owe this clarification to Boris Brandhoff. 
formally precise distinctions between predictability and determinism. Chaotic equations are deterministic, but their results are not predictable. Self-organizing systems are based on chaotic equations. They can generate emergent patterns. These patterns "dictate” to their constituents what they have to do, although they are part of the resulting pattern that they generate. From a theoretic point of view, it seems clear: If a description of the Deutsche Bank as a self-organizing system is to make sense, then the bank would also be an actor qua Deutsche Bank. Unlike selforganizing systems in the natural sciences, where the parts of self-organizing systems follow simple rules, an analysis of collective actors is practically difficult, because the individuals can act intentionally and be self-referential.

Nevertheless, in many cases, individual members of a group merely behave and do not act. This issue is taken into account in the distinction between collective actors and corporate actors. Each corporate actor is necessarily also a collective actor; however, a collective actor is not necessarily a corporate actor. Whereas, by definition, an institutional structure is a precondition of corporate actors, collective actors do not presuppose the existence of an external system of rules. Moreover, individuals within a collective actor may behave by following simple rules, whereas some of the individuals of a corporate actor act - embedded in an institutional framework of rules $^{3}$. Talk of collective actors usually refers to a mass of individuals acting as if they were a single agent, characterized by the special qualities of the mass. Therefore, scientific reasoning about when such a view can be adequate and why such a holistic view cannot be dissolved will constitute the focus of this paper. With the methods presented below, it is possible to give a rather unerring answer for collective actors, where individuals follow simple rules. This short abstract offers the central insights and outlines the answers provided in the following sections to the question of what makes a collective actor a collective actor sui generis.

In evaluating whether a system is self-organizing, we will make use of criteria from the natural sciences. In the natural sciences, theories of self-organization have been developed in order to understand emergence, while avoiding the aporias of substantialism and reductionism (cf. Schwegler 1992). The aim here is not to draw an absolute borderline, but to draw one that nevertheless does precisely delineate between clear cases of collective actors sui generis and other cases, where the denomination "collective actor" is only a metaphor. It could be that some readers think that this is unsatisfactory; nevertheless, the conceptual rapprochement can essentially enrich theoretical descriptions and explanations of collective actors. This text neither tries to offer an extensive review of theories of self-organization, nor does it strive to conceptually integrate different applications of notions like "emergence” or system from different works and disciplines. Probably, a coherent and consistent description beyond all theories of self-organization would be in vain, even more so since it is not clear whether identical concepts are being used or whether the similarity consists in the identity of the labels, referring to completely different things, which leads to a Babylonian confusion (cf. Küppers and Krohn 1992, p. 7). This is why

3 This distinction between beaviour and action ties up to von Wright (1971). Explanations about actions refer to certain thoughts and beliefst he agent had, whereas explanations about behaviour are not necessarily ,,intentionalist“. Methodological remarks about explanations on the intentional level can also be found in Dennett (1987). 
the aim here is to offer a conceptually coherent and consistent contribution in its own right, oriented towards conceptions from the natural sciences and deliberately filtering out other possible conceptualizations in order to allow a straightforward and determined answer to the question of what a collective actor sui generis is.

An initial, preliminary definition of emergence is taken from Camazine, Deneubourg, Franks, Sneyd, Theraulaz und Bonabeau (2001): "Emergence refers to a process by which a system of interacting subunits acquires qualitatively new properties that cannot be understood as the simple addition of their individual contributions” (p. 31). A similar definition can be found in Küppers und Krohn (1992, p. 7f), who characterize emergence as the sudden appearance of a new quality that cannot be respectively explained by the attributes and relations of the participative elements, but by a special self-organizing process dynamics. The idea that a new quality may be inherent to a complex or a whole - a quality that cannot be explained by merely considering the parts - is far from new. Aristotle asserted that the whole is more than the sum of its parts. Nevertheless, recently, in the 1970s, a paradigm shift occurred. Due to this paradigm shift, different phenomena from the social sciences and the natural sciences - be it thermodynamics, economic systems, social systems, or the brain - have come to be described as emerging and self-organizing processes.

The insight from self-organization theories in the natural sciences - that causal systems may organize themselves - goes far beyond Aristotle. This amazing insight leveraged theories of selforganization, and Prigogine acquired the Nobel-prize for his work on self-organizing processes in thermodynamic systems. Theories of self-organization were originally developed in physics and chemistry, which presented a new paradigm for many other sciences like biology, the neurosciences, economics, sociology and cognitive science. In a first phase, from the 1940s until the 1970s, mathematical models were developed that explained specific phenomena within particular sciences: Holling explained ecological systems; Prigogine explained systems within the domain of physical chemistry; Foerster, within cybernetics. During a second phase, the similarity of the different equation systems became palpable, as well as the analogy of the concepts used within the different theories. This led to "globalization" in a third phase (cf. Krohn, Küppers and Paslack1987; Dress, Hendrichs \& Küppers 1986).

The physicist, Haken, describes such self-organization processes - he tags them "synergetic processes" - as the "enslavement" of particular parts (like electrons) by the parameters for order. This happens, for instance, in a laser, where the order of the laser wave enslaves the atomic structure that goes along with the amplitudes of the laser. ${ }^{4}$ According to this view, this text about corporate and collective actors focuses on the question whether collective and corporate actors also have the potential to "enslave" their individuals, and, if they do, under which conditions such "enslavements” may occur. Please note that Haken understands “enslavement” as occurring

4 “...a wild, excited water surface will result. Similarly, in the present case of the lamp, the light field will be microscopically chaotic, consisting of very many uncoupled wave trains. When we increase the electric current through the gas, suddenly microscopically chaotic light waves may become entirely ordered. A giant, highly regulated light wave emerges” (Haken 2005, p. 72). 
without any leader, dictator, central plan or template. Although it seems clear that the term "enslavement" is inappropriate with regard to corporate actors - especially because our interest lies mostly in the generation of such orders in democratic structures - the methodology and theory behind the terms are pertinent for this paper. In the simplest case, it is possible to make direct and analogical use of such theories of self-organization from physics and chemistry to explain collective behavior. For instance, such theories are used to explain the emergence of patterns of coordinated applause or the emergence of pedestrian flows in concentrated areas like subway stations (cf. Schweitzer 1997). Although such theories merely describe and explain the behavior of corporate actors, they describe and explain essential elements of collective action and therefore important aspects for corporate actors by demonstrating how ordered structures may emerge in groups. This emergence occurs without a central plan or corresponding assignations for the individuals that lead to the intended holistic result, a complex "emergent” pattern. Due to the central plan in much collective action, not all such patterns would be considered emergent from the point of view of self-organization theories.

The perplexity about collective actors is part of the focus of this paper. This is why some of the relevant literature about self-organization will be largely ignored, especially literature that discusses the role of self-organization in the context of the mind-brain debate. The consideration of this debate would becloud the line of arguments of greater pertinence to corporate actors, because - besides the interesting questions about "how emergence comes about" and "how a whole can be more than its parts" - the mind-brain debate concentrates on the seemingly irreconcilable gap between the phenomenological mind and the brain, i.e. the relationship between our firstperson view of our feelings, thoughts, etc. and our third-person (natural scientific) view of the processes in our brain (cf. Roth 1987). ${ }^{5}$ Philosophers in this context further develop the notion of "emergence", for instance, by distinguishing between emergence and supervenience. For the sake of clarity and the conclusiveness of the arguments affecting collective actors, this debate is ignored here (an excellent overview of different fundamental philosophical positions and the respective aporia is given in Wiesendanger, 1987).

The remainder of the paper is organized as follows. The first section introduces the question of the adequateness and inadequateness of reductionist explanations for the description of entities. The considerations here neither draw on systems, nor, consequentially, on principles of selforganization, because the concept "self-organization" necessitates a systemic view. In other words, the first section discusses reductionism and holism on a very general level. The scope of these arguments goes far beyond self-organizing systems. Pragmatically, these arguments will be discussed within the domain of corporate actors.

Emergence is a concept embedded in system theory. Therefore, in the second section, the previous general considerations about holism are integrated and compared with the concept of "emergence”. In order to close the argument by precisely characterizing self-organizing systems and

5 Some comments to Haken's remarks about the enslavement of the brain by the mind can be found in Beckenkamp (1995). 
making the conceptual link between self-organization and emergence - which is done in the fourth section - the third section generally conceptualizes systems. This conceptualization is independent of whether these systems are self-organizing or not. Feedback loops are specified as an essential component of systems. They establish the essential precondition of system-theoretic models, where causes may also be effects and vice versa. System theory is essential for dynamic models such as ecological models and network thinking.

In the fourth section, mathematical chaos theory bridges the gap between the presentation of systems in general and the constricted consideration of self-organizing systems. The capability to behave or react chaotically is a necessary precondition of self-organization. Nevertheless, there are striking differences in the answers - given from theories of self-organization in biology, economics or sociology - to the question "What makes the whole more than the sum of its parts?" The fracture with respect to the understanding and conceptualization of "chaos", "complexity" and "self-organization" seems particularly salient at the borderline between formal mathematical and natural sciences, including economics, and the social sciences such as sociology. Sometimes it creates the impression that originally well-defined concepts from mathematics and the natural sciences are metaphorically used in the social sciences. This is a further reason that this paper concentrates on conceptualizations of self-organization from the natural sciences.

The fifth section integrates the arguments from a system-theoretic point of view given in sections two through four with respect to collective and corporate actors. Due to his prominence, all five sections deal to some extent with the sociological system theory of Niklas Luhmann, especially in those sections in which there are rigorous and important differences between his conception and the view given in this text. Despite Luhmann's undoubted prominence in sociology, the present text strives for a more analytical and formal understanding of social systems and tries to find a basis for another methodological approach.

\section{When is the whole more than the sum of its parts?}

\section{When the whole is explained by its parts: reductionism}

Even in the natural sciences, the issue whether the whole is more than the sum of its parts is not new: "There is an age old controversy in biology between the two opposite extremes of 'reductionism' and 'holism'. The former finds concurrently its most outspoken advocates in the field of 'molecular biology'” (Weiss 1969, p. 10). It may be noticed that, since the publication of Weiss's article, a shift has taken place that actually makes genetic reductionism the most representative form of reductionism in biology. Generally, reductionist methodology decomposes complex phenomena into individual parts and thus provides explanations. However, the decomposition is not sufficient for a reductionist explanation, because the relations between the individual parts also have to be specified. One consequence of such a decomposition of complex objects into simpler parts is a different way of looking at things, or, in Putnam's words, a transformation from one class of assertions to another class of assertions (cf. Putnam 1981). 
Reductionism, with respect to a class of assertions (e.g. assertions about mental events) is the view that assertions in that class are 'made true' by facts which are outside of that class. For example, facts about behavior are what 'make true' assertions about mental events, according to one kind of reductionism. For another example, the view of Bishop Berkeley that all there 'really is' is minds and their sensations is reductionist, for it holds that sentences about tables and chairs and other ordinary 'material objects' are actually made true by facts about sensations (Putnam, 1981, p. 56).

With the second example, in order to emphasize the generality of his definition, Putnam deliberately describes one reductionist approach that has now largely been rejected in the natural sciences. Reductionism can be found outside the natural sciences as well. In the natural sciences it is common to think of reductionism in hierarchies and at different "levels" (cf. Weiss 1969) from atomic physics, via physics, to inorganic chemistry, organic chemistry, physiology and biology. But, as opposed to the picture suggested by this list, by-passes or branches may occur, with the consequence that the different ways of looking at things are of a looser order than in a strict hierarchy. Therefore it is adequate to avoid the term "levels" and to choose, as Putnam does, a term such as “class of assertions”, or Wittgenstein's term “ways of seeing things”. The latter term will be used in the following. Now, the central claim of reductionism is that these different ways of seeing things are reducible to one distinguished way of seeing them (cf. also Putnam 1981). The biologist Virchow, for instance, understood the organism as a complex of organs, and a specific organ as a complex of cells. As the founder of cellular pathology, he tried to explain the behavior of organisms and their diseases by the functions of the cells.

In psychology, similar forms of reductionism can be found. Historically, Pavlov tried to explain human behavior by focusing on associations between elemental events. Later on, behaviorism tried to reduce the repertoire of human behavior to chains of stimuli and responses (cf. Gregory 2004). Another form of reductionism can be found in social cognition - a current stream in social psychology - where the behavior of groups is explained by referring to the cognitive contents of the individuals of that group. Looking at collective and corporate actors, such an approach poses the question of when the behavior of the collective actors can adequately be explained by the behavior of its individuals in their network of mutual relationships, and when it cannot. ${ }^{6}$ One approach to answering this question will be given in the following by looking at arguments for necessary changes in our ways of seeing things. More generally, the arguments are an answer to the following question: Why is it rational to change from a reductionist to a holistic point of view, and under which circumstances is it even necessary?

6 So, this question already comes up before system-theoretic considerations are taken into account. Thus, one variant of the question whether individuals are the causal elements of corporate actors can already be posed here. 


\section{When the whole cannot be explained by its parts: about holism}

Putnam (1981) rejects the doctrine that the laws of "higher-level” sciences (like sociology) are reducible to the laws of lower-level sciences (like biology). Although the behavior of a system can be deduced from its description as a system of elementary particles, it is not necessarily explained by this description. Putnam gives an example, referring to two objects from a holistic point of view: a board with two holes, and a square peg. One hole is squared, allowing the peg to fit in; the other hole is round, not allowing the peg to fit in. From a holistic point of view, the fact that the peg fits into the first hole and not the second is explained by referring to the rigidity of the board and the pegs and the geometric cross section of the peg and the geometric form of the holes. This is a more valid explanation than a reductionist calculation that refers to the elementary particles with their positions and velocities, which "after a heroic feat of calculation", proves that the elementary particle cluster A (the peg) will fit into the region I (the first hole) that is surrounded by the elementary particle cluster B (the board), but not into region II (the second hole). Though the latter is a valid deduction, the relevant facts are buried in a mass of irrelevant information, and, therefore, this deduction is not an explanation. According to Putnam, a valid explanation makes the relevant features salient and leaves irrelevant features in the background.

In a thought experiment, he supposes that a fact $\mathrm{F}$ (like the fact that the peg fits into the first hole) can be deduced by relevant facts $G$ (like the rigidity of the peg and the boards) and thus genuinely explained, and that it can be deduced by irrelevant facts I (like positions and velocities of particles). He doubts whether $\mathrm{G}$ and I are an explanation of F. If a new mathematical formalism $H$ is now created from $G$ and $I$ in such a way that $G$ and I cannot be recovered from $H$, then F can be deduced from $\mathrm{H}$, but $\mathrm{H}$ - like $\mathrm{G}$ and $\mathrm{I}$ - is not an explanation of F. Putnam's argument shows that deduction and explanation are two different things. Explanations have to recur to the relevant facts, and mostly (or only) to the relevant facts. There is no explanation if the relevant information is hidden within a mass of irrelevant facts. ${ }^{7}$

A critical reader might object and ask about the concept of "explanation”. If a board and a peg can be reduced to their atomic structure, and the observed behavior can be deduced from this structure, why shouldn't the phenomenon be explained through this reductionism? However, Putnam himself highlights the main point of his argument. An integrating way of seeing things allows the identification of behavioral patterns where the microstructure is simply irrelevant. It is possible that one and the same behavior can even be deduced from an infinite number of different microstructures. ${ }^{8}$ This is why phenomena, described in accord with an integrating perspective, may be dependent on more than their microstructure. It is the macro-relation - a relation that subsumes a whole set of individual parts in one relationship - that matters and provides an explanation. In the discussion of reductionism, it is often overlooked that not only the "atomic"

7 Due to the unrevorable property of $G$ and I that lead to $H$, the argument is not identical to Ockham's razor ("entia non sunt multiplicanda praeter necessitatem", which translates to "entities should not be multiplied beyond necessity").

8 In Artificial Intelligence, this argument is often given as a reason that intelligent behaviour should be possible on a silicon base and does not necessitate neurons (e.g. in. Haugeland 1981). 
view of the objects under purview matters, but also the relationships between the objects. The obliviousness to this is reminiscent of the situation at the beginning stages of measurement theory, where a scale was grasped as a mapping of objects onto numbers rather than as a mapping of an empirical relative onto a numerical relative (cf. Suppes and Zinnes 1963).

An example from graphical computer applications may illustrate this point. A graphical object like a rectangle can be constructed on a screen from two vertical and two horizontal lines that touch each other at the endpoints. Similarly, a rectangle can be put on a screen like that. While granting a congruency between the two constructions, nevertheless, the difference is tremendous. The object triangle cannot be decomposed into its individual parts; it hides other objects; it can be put in the background behind other objects, etc. The reason for this difference is that the four relations between the four individual parts are subsumed in one macro-relation. This is indeed what constitutes the change in the way of seeing things. Somebody who ignores this subsumption is blind to the regularities that result from integrating this into one macro-relation, like the constant sum of angles, the constant distance between the parallels, the parallelism itself, etc. The macro-relation is contained in the object itself, and not in the parallel consideration of different constraints.

Hofstadter (1999) illustrates the interplay between holistic and reductionist ways of seeing things in a conversation between four of his protagonists: Achilles, the tortoise, the crab and the anteater. Achilles sees clearly the word MU (see Figure 1), but the crab disagrees and argues that it is obvious that there is the word "holism" where Achilles hallucinates an "M". The anteater sees neither an "M" nor "holism", but insists on the repetitions of the word "reductionism". Every protagonist refers to a different level of resolution in the discussion of the illustration, and none of them sees the "MU" on the fine-grained micro-level. 


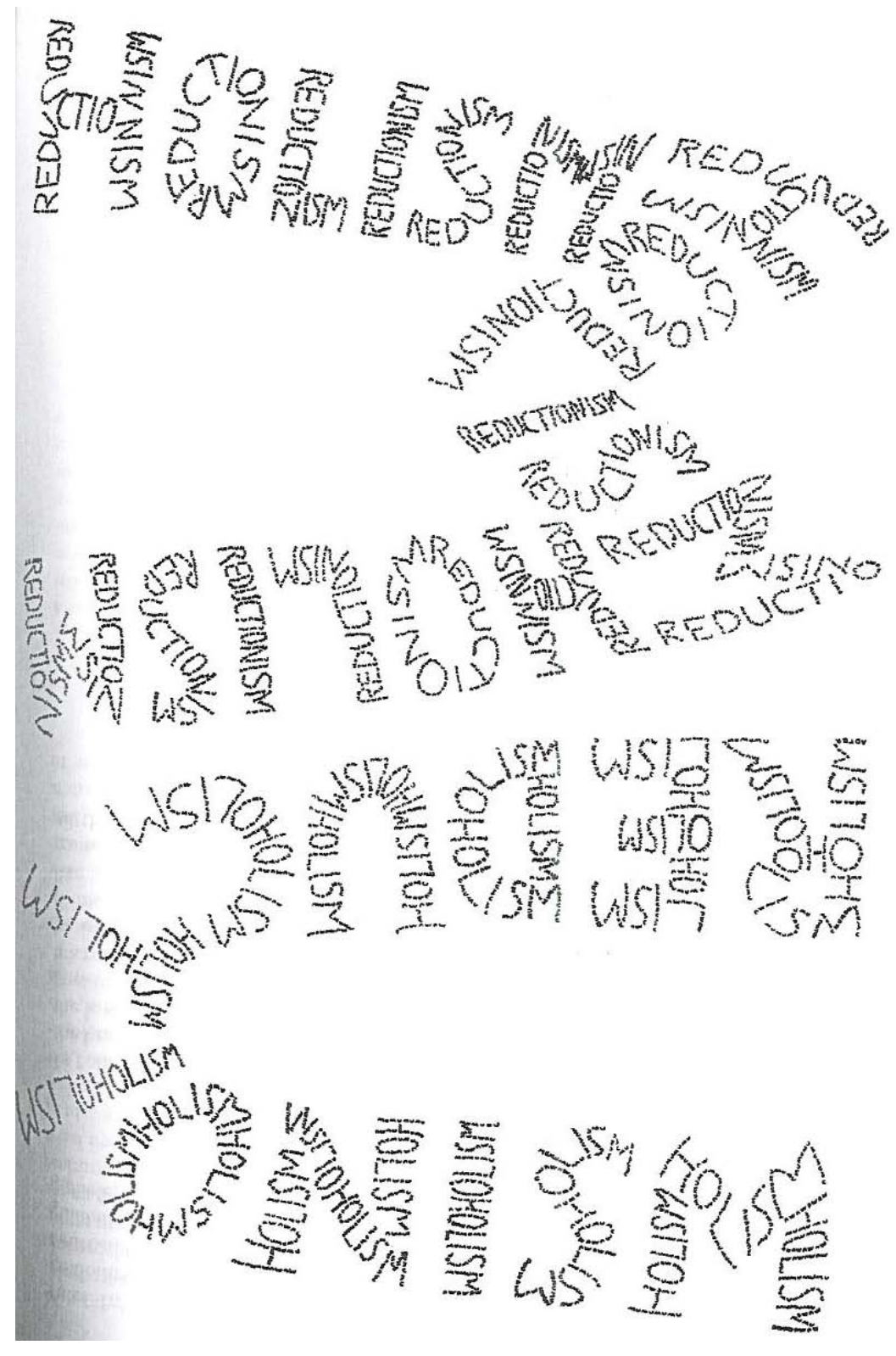

Figure 1: (copied from Hofstadter, 1985, p. 310).

The same phenomenon can be illustrated with "picture puzzles", such as the bride and mother in law (cf. Figure 2). It takes some time to see that there are two possible interpretations of this picture. The chin of the bride is the nose of the mother-in-law, her ear is an eye, and her necklace is the mouth, respectively. And even once both interpretations have been perceived, it is still difficult to switch between the two views deliberately. 


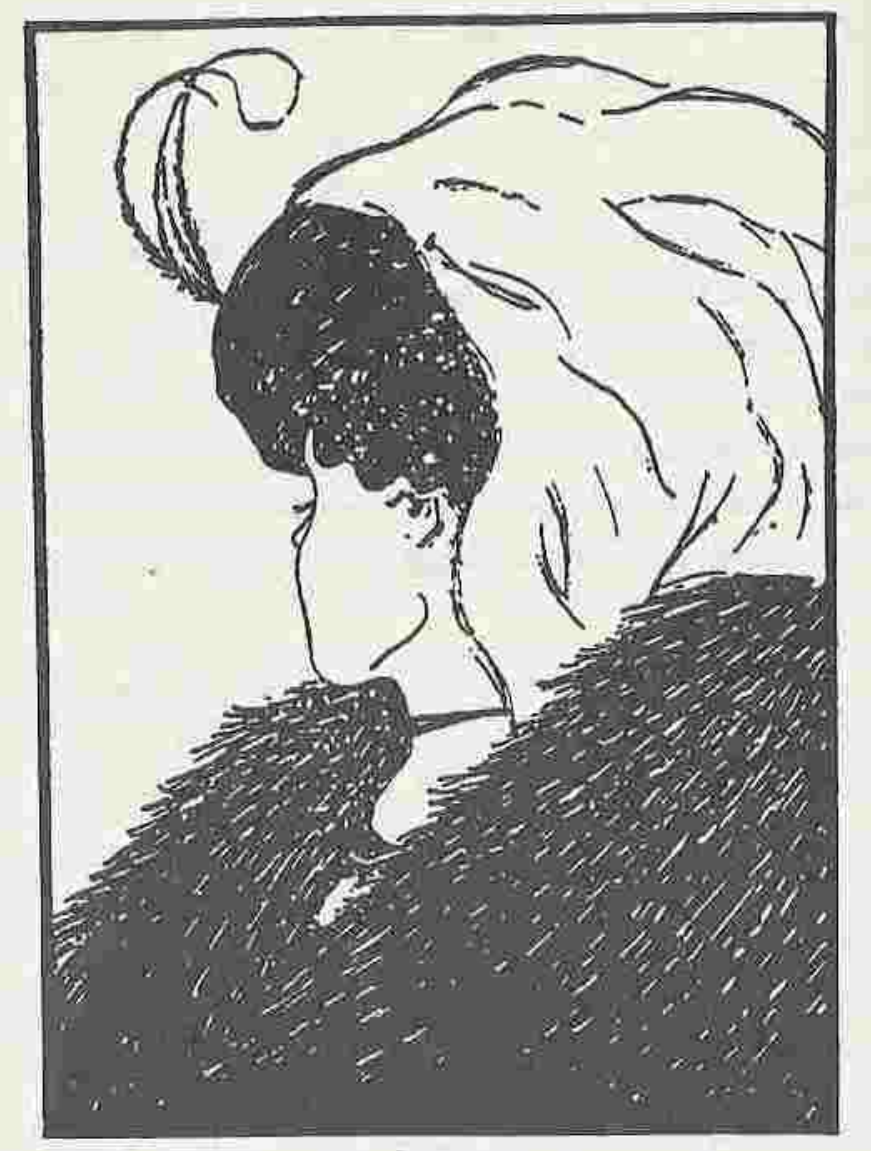

Figure 2: "Bride and mother-in-law" from Metzger (1975, p. 144).

The examples demonstrate that, depending on the context, certain relational arrangements may be the focus of interest. Good explanations distinguish themselves from bad ones by taking into account the relevant relational arrangements. In certain contexts, reductionist explanations can be too rich in detail and thus dilute good explanations or even result in them disappearing in a fog. Now, the relevant question with respect to collective actors is whether there are arrangements of relationships that are characteristic for such actors that cannot be explained (in Putnam's sense) by the interrelations between individual actors and the qualities of the individuals. There is every reason to believe that there are. Think about the situation of a teacher in an auditorium with about 100 participants. The mass is sufficient to make it hard or even impossible to speak directly to individual participants if you need to direct the whole auditorium ${ }^{9}$ to undertake some coordinated action. You would have to address individual participants to accomplish small tasks, for example, if you wanted someone to give you a piece of chalk. If, however, the goal is to move the mass as a mass - for instance, if you want all the participants to leave the auditorium and to meet at a specified point outside - the method and form of communication must be adapted to this task. This difference is especially evident in the context of TV, where the communication of the speakers leads to the phenomenon of "parasocial” interaction, a one-sided relation in which one party knows a great deal about the other but the relationship is not reciprocal.

9 Olson (1965) describes different critical masses of groups that are necessary in order for groups to gain new properties respectively. 
The consequence of this form of communication can be a one-sided friendship, where the individual feels a warmth and understanding for the speaker similar to the feelings the recipient has for his close friends. The communication from the speaker, however, addresses a mass, although many individuals have the feeling of being addressed personally. There is an illusion of a personal relationship on the part of the TV viewers (or, in our case, perhaps the class?).

\section{Holism und emergence}

At the beginning of this text, a preliminary definition for emergence was given: "Emergence refers to a process by which a system of interacting subunits acquires qualitatively new properties that cannot be understood as the simple addition of their individual contributions" (Camazine et al. 2001, p. 31). Subsequently there was a presentation of some initial arguments, giving some idea of how a whole acquired qualitatively new properties. Although Putnam (1981) himself recurs to systems, it is important to note that his argument is very general and can be made without reference to systems, but for any decomposition of an arbitrary object (not necessarily a system) into its parts. Therefore, his argument is no argument for emergence in the strict sense, although it also explains the acquisition of qualitatively new properties that cannot be explained by the properties and mutual (pair-wise) relationships between the elements and that therefore are not to be seen as the simple composition of the whole from its elements.

In other words, the previous section dealt with the following question: How can we account for the fact that a whole acquires new qualities that can not be explained by referring to the parts and the mutual interrelations between these parts? It was demonstrated that this question stands in close relationship with the question about when a holistic view, as opposed to a reductionist view, is justified and when it facilitates better explanations or any explanations whatsoever. This question was meaningful and able to be answered without any system-theoretic assumptions, i.e. without looking at systems or processes. It was shown that there is an essential reason for adopting the holistic perception if particular elements and their particular relations with each other are integrated into a macro-relation. Qualitatively new properties may be inherent to such macrorelations, and these qualities cannot be made accessible by the micro-relations alone. Independent of tautologies (deductions) and the Hempel-Oppenheim scheme, the argument provides a self-sufficient form of explanation. This explanation consists in a specification of the parts and their micro-relational structure, which must be present in order to create the macro-relationship and thus the new quality. In other words, sufficient conditions on the micro-level can be specified that allow the creation of the new properties on the macro-level. By arguing that a holistic view need not be completely dissolvable into a microstructure, a third form, in addition to the "either/or" choice between reductionism and holism, was introduced: a constructive in order to. ${ }^{10}$ It is a bottom-up approach from reductionism to holism, specifying sufficient conditions on

10 Examples of such scientific explanations are given in classical papers from neurophysiology, for instance, when von Holst opposes reflex arcs to oscillators or "pacemakers", i.e. bio-rhythms that cannot be reduced through explanations that merely use reflex arcs. Galistel's reader (1980) assembles such classical papers, 
the micro-level. ${ }^{11}$ The qualitatively new property, however, is not contained in the microstructure, but a macro-relation.

That also provides initial arguments for the inadequacy of reductionist explanations of collective and corporate actors. Corporate actors are especially characterized by a complicated network of well-defined interrelationships and integrating relations with respect to communication and responsibilities. Different subsets and higher order relationships between them can often be found in this context. Therefore, the relevance of the arguments for corporate actors seems obvious. Collective actors, however, are often characterized by a loose relationship between the individuals comprising them. Hence, the relevance of the arguments solely for collective actors is not obvious. If, however, such macro-relationships can be identified within collective actors, for instance, in movements, then skepticism about purely reductionist explanations is appropriate.

Besides this identification, other profound arguments can be given. Principles of self-organization may intensify the skepticism about reductionist explanations. In the following, this aspect will be discussed more intensively. The clear relevance for collective actors is evident, and, in contrast to the argument given before, here there is no need to make any constrictions with respect to the fulfillment of additional circumstances, such as the claim that the collective actor must already have some characteristics of a corporate actor. If the principles of self-organization are fulfilled, then the behavior of collective actors cannot be adequately explained by merely focusing on the behavior of the participating individuals.

An important point is that predictability and determinism (of an object of investigation) are two different things, and the principle difference between them can be explained by mathematical reasoning (cf. Gleick 1987). Under certain conditions, it may be that deterministic systems are not predictable in principle. However, if, in a given system, determinism and predictability become separated, an abandonment of a reductionist view and a shift to a holistic view can pay off in a better ability to identify regularities, and correspondingly better predictability. Again, in fact this argument is independent of systemic concerns and concerns with processes, although it is usually given in a systemic context.

The arguments given here stand in contradiction to Luhmann's (1984); he justifies the necessity of abstracting away from the subject if social systems or social units are to be explained, and he directly alludes to the self-reference of self-organizing systems. In doing so, he does not account for self-reference, but presumes it. In the text at hand, it is demonstrated that the independence of a holistic view can be substantiated from the "bottom up", beyond any concerns with a systemic view - i.e. without the related assumptions and preconditions - and not exclusively "top-down"

with the intention of providing a better understanding of such explanations. A philosophical and epistemological view of such explanations is given in Ros (1994).

11 For pragmatic reasons, the discussion concerning why this does not necessarily imply an ontological view is not debated here, although this conceptualization may be congruous with positions from analytical philosophy and philosophy of language, such as those in Putnam's (1990) epilogue and in Ros (1990 -mainly vol. III). An epistemological discussion lies outside the scope of the question dealt with in this text and runs counter to the pragmatic goal here of offering a concrete methodological view. 
by a "constitution from the top" (cf. Luhmann 1994, p. 43). In contrast to Luhmann (1984), the arguments given here do not presume autopoeisis in a system with self-reference.

The succeeding examination of systems and self-organizing systems will broaden the issue of the necessity of holism to include the question of emergence in the strict sense. Even without presuming that self-organizing systems are the matter under discussion, it is possible to identify good reasons that justify a change in the way of seeing things from a micro- to a macro-view of things. This, however, is not emergence in the strict technical sense. This is why, besides the answers given so far, arguments that base emergence on the principles of self-organization will be discussed in the following. This is the most complicated and challenging endeavor in answering the question, "When is the whole more than the sum of its parts?"12 Chaos theory will provide the essential formal precondition for emergence: once the systems are characterized by mathematical formulas, chaotic dependencies between the output variables and the input variables can be specified as an essential feature of self-organizing systems. Therefore, system-theoretic considerations allow us to broaden the arguments that justify a change from a reductionist to a holistic point of view, arguments for “qualitatively new properties”.

In the following, these genuine system-theoretic arguments will be presented. First of all, the concept "system" will be specified. After that, essential characteristics of self-organizing systems will be specified. The section concludes with a discussion of corporate and collective actors, asking whether and/or under which conditions it makes sense to conceptualize these as selforganizing systems.

\section{Systems}

\section{Systems and self-organization}

Order may emerge without central planning or given templates, and this is what can be observed in self-organizing systems. When the system-theoretic conceptualization of self-organization was introduced in the 1960s and in the 1970s, it was integrated into different system theories from the natural sciences, such as physics, chemistry, biology and computer science. Adaptations for the social sciences and humanities followed, in particular in economics and sociology, where Niklas Luhmann introduced the most important and established adaptation.

Due to the formal precision and transparency of the natural sciences, the following sections will introduce the conceptualization of self-organization within this framework. First of all, systems will be characterized, then essential insights from chaos theory that are relevant for a precise determination of chaotic systems and self-organizing systems will be introduced. This background will enable us to understand why chaos is necessary (but not sufficient) for self-organizing systems.

12 And, in addition to that, Luhmann (1994) makes the claim that the parts are constituted by the whole, and therefore a bottom-up analysis of the self-organizing system is impossible. 


\section{Characterizing attributes of systems}

The scientific view of self-organization presupposes a system-theoretical view. First conceptualizations of system theory were presented in the 1940s by the biologist, Ludwig von Bertalanffy, and, for instance, in 1948 advanced by Norbert Wiener in his pioneering work in cybernetics; this work was concerned with data flows and/or information flows. In psychology, system theory was mainly introduced by a work of Miller, Galanter and Pribram (1960). By modeling human behavior with "TOTE” units (test-operate-test-exit), they introduced alternative ideas to the stimulus/response chains used until then by behaviorism. Besides that, some other works were stimulating the "cognitive turn” in psychology.

The search for definitions of systems in the literature is frequently unsatisfactory. Though they may be correct, in fact, they are so universal that a system cannot be conceptually differentiated, for instance, from a causal chain. For instance, the American Heritage dictionary defines a system as "a group of interacting, interrelated, or interdependent elements forming a complex whole”. A similar definition can be found in the Blackwell dictionary of social thought, with an adaptation to Niklas Luhmann's view:

Systems are complexes of elements and relations, separated by boundaries from their environment, which is always more complex than the system itself (Outhwaite 1994, p. 658).

Or in the Blackwell dictionary of sociology:

In general, any system can be defined as a set of interdependent elements or parts that can be thought of as a whole. In this sense, we can think of a motor or the human body as a system (Johnson 2000, p. 296).

Whereas some system theorists, like Ludwig von Bertalanffy (cf. Cambridge dictionary of philosophy, Audi 1999, p. 898), think that systems are "real", others think that a system is not a natural category but a convenient cognitive construction (cf. Klir 1991). Many authors also claim that the parts of a system can also be system or a subsystem respectively (cf. Liening 1999, p. 54).

In the following, a characterization of systems will be given that is based on literature about complex systems, identifying relevant concepts and views. Describing an object of research as a system implies that the elements or components are embedded in an interrelational structure. The relations themselves are usually directional, such that it makes sense to speak about a "flow" from one component to another if these elements are connected. To facilitate inspection, such relational structures are often represented in diagrams: the components are represented by nodes, and the directional relations between the components by arrows. The broad range of applications of system-theoretical models in the natural sciences, the social sciences and even in the humanities is due to the independence of the components from the concrete substance: For instance, such components could be particles, cells, persons, transistors, computers, etc. System theory is also independent from the quality of the interrelationship between these components (like data or 
information flow, flow of energy, or flow of matter, and, besides these physical categories, categories like flow of goods or money, etc.).

Beyond that, if an object being studied is described as a system, it is necessary to specify the borders between the system and its environment (that again may consist of further systems). In extreme cases, it is possible to investigate closed systems, i.e. systems without any relations to the environment. However, open systems are commonly of concern, where such a demarcation between system and environment has to be effected. A system can also be closed with respect to one relation and open with respect to another. Such conceptualizations can be found in biological models of "radical constructivism", where autopoieitic systems are open to matter and energy, while at the same time being operationally closed (cf. de Meer and Koppers 2005, p. 236) For instance, Gerhard Roth (1980 1987) grasps our brain as such an autopoietic system that is operationally closed with respect to information, instruction or control.

A third feature of systems is the formation of feedback loops within the relational structure of the components. ${ }^{13}$ In the simplest case, something flows both from component A to component B and independently from this flow (like its quantity and its characteristic), and the internal state $\mathrm{B}$ reacts by providing $A$ with a flow from $B$; and this again results in a change of the flow from $A$ to $B$, of course, dependent upon the internal state in $A$ and the flow from $B$.

Basically, there are positive and negative feedback loops. Positive feedback loops are selfreinforcing. They accelerate the state variables of the system, whereas negative feedback loops are regulating. ${ }^{14}$ For instance, positive feedback loops can occur if somebody speaks into a microphone that is near a speaker. In this case, the announcement comes from the microphone to the amplifier, from there to the speaker, and from there it is cycled back into the microphone. The consequence may be a permanent recycling and amplifying such that the initial sound is transformed in an unbearably loud tone. Thermostats provide an example of negative feedback loops. The warmer the temperature in a room, the less hot water is allowed into the radiator by a valve. If the temperature drops, the thermostat opens the valve, allowing more hot water to come into the radiator. Thus, the room warms up again. This is negative feedback that keeps the temperature constant. Feedbacks can also occur indirectly, and they can concern more than two components. In this case, it is often not possible to describe the feedback as a mere positive or a mere negative feedback. However, if only two components are in view, for most of the systemtheoretic models, the relationship between these components can clearly be identified as either positive or negative. Corresponding graphical representations depict such clear relationships, for instance, by labeling an arrow with a minus or a plus sign, where the arrow represents the direc-

13 Sometimes one-component systems can be found in the literature. This characterization excludes them by definition. There are good reasons for that exclusion, because one-component systems can be described as simple causal chains as well, whereas such a view is excluded in feedback loops. Causal chains become causal cycles, and cause and effect permanently switch. Following the formal characterization of system structures given in Czayka (1974, p. 28ff.), the characterization given here requires that symmetrical structures can be found in the relational network.

14 The term "regulating" is chosen deliberatively here, and not "slowing". The reasons will be given below, when negative feedbacks are discussed in more detail. 
tional relation between two components (e.g. Metzler 1987). Below, negative and positive feedback loops will be presented in more detail.

\section{Examples of open systems with different feedback loops}

Negative feedback loops: The regulation of blood sugar levels can be modeled in a simple systemic model with negative feedback loops. The corresponding system consists of an environmental component, "sugar consumption", and the two components of the system, "insulin production" and "blood glucose level”. The consumption of sugar from the environment raises the blood glucose level, triggering a release of insulin in the pancreas. This again results in a storage of glucose and thus in a decrease in the blood glucose level. The environment "disturbs" the system by raising the value of one component of the system. The system itself compensates for this "disturbance".

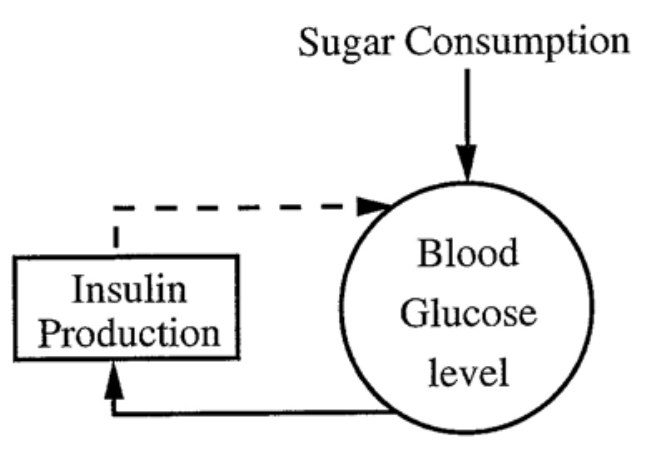

Figure 3: A negative feedback loop (example from Camazine et al. 2001, p. 16).

The respective figure represents system components that measure values as circles and system components that "produce" something as rectangles. Instead of labeling the arrows with signs (plus and minus), this figure represents the relationship between two components by dashed and continuous lines. Dashed lines correspond to negative relationships and continuous lines to positive ones.

Another example of a negative feedback loop is the shivering of our body in reaction to a drop of temperature in the environment. Again, the drop of temperature is a disturbance from outside. It is compensated for by a higher combustion of energy reserves within the body, made possible by shivering, until the temperature reaches the set-point again. 


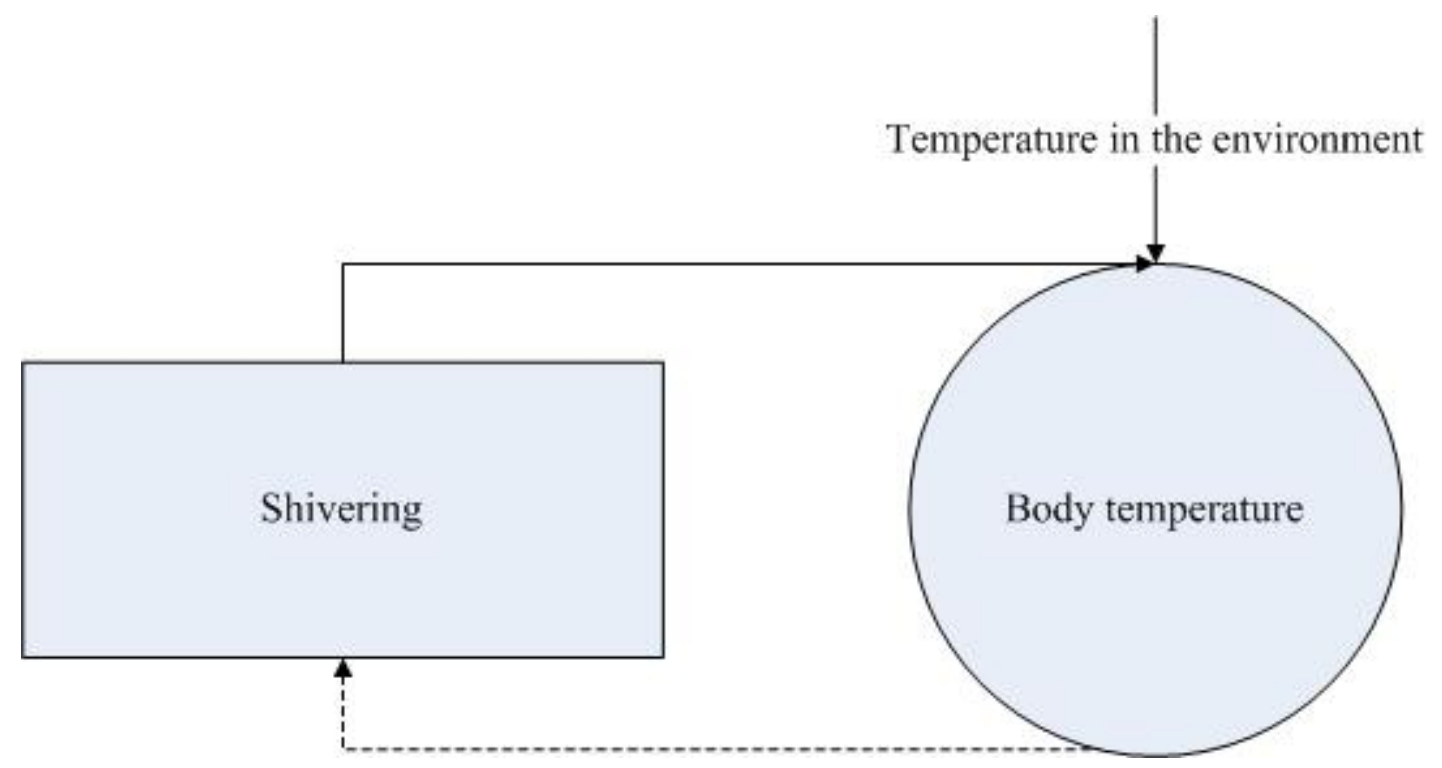

Figure 4: A negative feedback loop (adapted from Camazine et al. 2001, p. 16).

In a similar way, the thermostat mentioned above regulates the temperature in a room. The degree of shivering corresponds to the opening of the valve, the body temperature to the temperature of the radiator, and the "disturbance" is the environmental temperature in this case as well.

Beyond that, from the examples and their graphical representation, it is clear that negative feedback loops are not a simple inversion of positive feedback loops, because two components of a system are not simply connected by two negative arrows but by a negative and a positive arrow. The former case would imply that the system is brought into a static equilibrium as soon as the internal state 0 has been reached within the system. This is why the claim that negative feedback loops merely brake or slow things down is misleading. Often, the function of negative feedback loops is to keep a system close to a set-point or to bring it back to this set-point respectively. If the current value is below the set-point - making use of the metaphors above - the system "accelerates”. If, however, the current value is above the set-point, then the system slows down or "brakes". Thus, the characteristic dimension of negative feedback loops is that they work against disturbances from the environment.

The TOTE units (Miller, Galanter und Pribram 1960) mentioned above also provide an example of negative feedback loops. Here again, actual values are compared with set-points (Test). In case of deviations, the system reacts (operates), leading to a reduction of the difference in closed systems - in an open system, the environment may cause a disturbance, preventing a reduction. After the reaction, the system compares the actual value with the set-point once more. This sequence is repeated until the difference is eliminated. Establishing the concordance with the setpoint may now enable other actions of the system (Exit), which again are represented as TOTE units.

Positive feedback loops and interlinked feedback loops: In contrast to negative feedbacks, which may stabilize open systems after disturbances from the environment, the long-term conse- 
quence of positive feedbacks is a change within the system itself. Populations that explosively grow can be represented by positive feedback loops. Humans "produce" offspring, and the more humans there are, the more offspring (assuming a constant number of children) produced, so that the population grows over time. Without sufficiently strong negative feedback loops (like contraception or death rates), the consequence of positive feed-back loops are "snowball" effects. In this example, as long as the birth rate is higher than the death rate, the whole system is under the influence of the positive feedback loop.

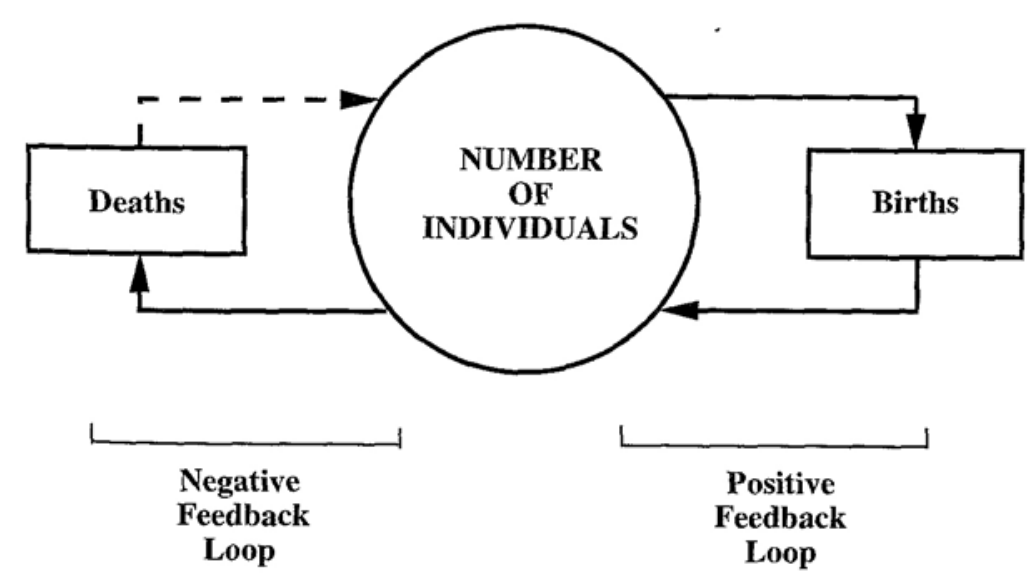

Figure 5: A positive feedback loop (from Camazine et al. 2001, p. 17). Please note that the whole system is represented as a closed system.

According to the grammar of the graphical representations given above, the measurement component in this example is the number of individuals. If the number is high, the number of deaths and of births "produced" is high as well. In this model, increasing the number of individuals increases the number of deaths as well. However, this increase is not necessarily proportional to the number of individuals. Due to epidemics or famine, the number of deaths can increase disproportionately. ${ }^{15}$ This is where the negative feedback comes in. The positive feedback results from the assumption that a higher number of individuals is accompanied by a higher number of offspring. Due to the concatenation of the two feedback mechanisms, the system may drift both in a decline (as in "developed countries") and an increase (as in "third world countries") in the number of individuals. The concatenation of negative with positive feedback loops is typical for many biological systems and underlies biological clustering processes such as honey bee clusters or bark beetle colonies under the bark of an afflicted tree. It underlies the biological synchronization of herds and swarms, as well as the movement patterns of schools of fish or the flashing patterns of fireflies. Often, the negative feedback comes from the environment.

15 Such systems with nonlinear kinetic relations and a permanent influx of energy, matter, information or similar inputs from the environment are referred to as dissipative systems. "In these open systems, in which there is a continual influx of energy or matter, reactions occur far from chemical equilibrium, and structures emerge through interactions obeying nonlinear kinetics. Such structures are called dissipative. At about the same time, Haken (1978) introduced the concept of synergetics as a unifying approach to pattern formation in various disciplines” (Camazine et al. 2001, p. 30). 
The preceding examples indicate that positive feedback is a powerful mechanism for building structure in biological systems. Without an antagonizing inhibitory mechanism, however, the process may become uncontrollable. Negative feedback brakes and shapes what could otherwise become an amorphous, overgrown structure [...] In place of explicitly coding for a pattern by means of a blueprint or recipe, self-organized pattern-formation relies on positive feedback, negative feedback, and a dynamic system involving large numbers of actions and interactions [...] Fluctuations can act as seeds from which patterns and structures are nucleated and grow. The precise patterns that emerge are often the result of negative feedback provided by these random features of environment and the physical constraints they impose, not by behaviors explicitly coded within the individual's genome (Camazine, Deneubourg, Franks, Sneyd, Theraulaz und Bonabeau 2001, p. 26).

The examples illustrate: Coupling positive with negative feedback loops is a necessary precondition for the formation patterns technically characterized as "emergent structures".

Self-enhancing positive feedback coupled with antagonistic negative feedback provides a powerful mechanism for creating structure and pattern in many physical and biological systems involving [a] large number of components (Camazine, Deneubourg, Franks, Sneyd, Theraulaz und Bonabeau 2001, p. 20).

In the following, it will also become clear that such patterns may lead to evolutionary advantages. However, before looking into that, it makes sense to elucidate the concept of "selforganization” against the background of the information about systems provided above.

\section{Self-organizing systems}

First of all, a tentative definition may be helpful. Self-organization exists if - independent of the intentions of an organizer or a central plan - regular or arranged patterns emerge from the interactions in the system itself. Indeed, concepts like "regular" or "arranged” or "central plan" are not precise. Nevertheless, this preliminary rapprochement can ameliorate our understanding of the initial specifications. Above all, it is important to note that concepts such as "order" or "regularity" are conceived in a system-theoretic framework. An author keeping his task schedule for the day or the month is not self-organizing in the sense of the preliminary definition, although he might be conceptualized as self-organizing from the point of view of action theory. Although there may be nothing wrong with viewing the author as a system - both in ordinary language and in science - it is not common to describe an author by referring to positive and negative feedback loops. $^{16}$

The concept "self-organization" stands in very close conceptual connection to emergence. That is, the order or the pattern of a system is emergent if and only if it can be created by such simple

16 If a medical doctor examines the aforesaid author, then he might well have a systemic view of his patient and be interested in the functionality of different sub-systems, like the cardio-vascular system. However, in this case, the consideration of the author in this role is left aside. 
feedback loops, and not, for instance, by a central plan that has been decomposed into different sub-plans or sub-rules. If emergence is observed in a system, this means that the system is selforganizing.

Self-organization is a process in which pattern at the global level of a system emerges solely from numerous interactions among the lower-level components of the system. Moreover, the rules specifying interactions among the system's components are executed using only local information, without reference to the global pattern. In short, the pattern is an emergent property of the system, rather than a property imposed on the system by an external ordering influence [...] As used here, pattern is a particular, organized arrangement of objects in space or time [...] In each case [...] a system of living cells or organisms builds a pattern and succeeds in doing so with no external directing influence, such as a template in the environment or directions from a leader. Instead, the system's components interact to produce the pattern, and these interactions are based on local, not global, information (Camazine, Deneubourg, Franks, Sneyd, Theraulaz und Bonabeau 2001, p. 8).

However, the reverse is not true. Self-organizing systems may run out of control as well. If they do, instead of stable patterns (in certain time intervals), chaotic behavior can be observed, for instance, when fluid streams swirl in turbulences, ${ }^{17}$ or in escalating behaviour, as found in the population example given above, when exponential growth overrides the retarding forces and the population level runs out of control.

\section{How to empirically decide about self-organization}

In practice, often it is hard to decide whether the rules of the individual agents are simply parts of a complete plan (as at a construction site) or whether the emerging and organized pattern really stems from a mere cluster of individual agents that behave independently of a central plan, according to their simple rules.

Technological systems become organized by commands from outside, as when human intentions lead to the building of structures or machines. But many natural systems become structured by their own internal processes: these are the self-organizing systems, and the emergence of order within them is a complex phenomenon that intrigues scientists from all disciplines (Yates et al. 1987, nach Camazine, Deneubourg, Franks, Sneyd, Theraulaz und Bonabeau 2001, p. 7). ${ }^{18}$

So it is really an intriguing question whether schools of fish have a leader or whether the coordinated movement patterns emerge from the simple rules that fish follow in determining the direction and the speed they swim. Nowadays it is accepted that common schools of fish are selforganizing systems:

17 More on that below with the presentation of the Bénard-Rayleigh convections.

18 This is only partly true because recent research also strives for self-organized systems and technologies. 
A member of a fish school does not need to know the long-range direction taken by the school or even the precise trajectories of all or any of its neighbors. It needs only apply a few simple rules of thumb, such as these: Approach neighbors if neighbors are too far away; Avoid collisions with nearby fish; If the first two rules have been obeyed and neighbors are at the "preferred" distance, then continue to move in the same direction (Camazine, Deneubourg, Franks, Sneyd, Theraulaz und Bonabeau 2001, p. 23).

The question whether a system is really self-organized or whether a - perhaps well-hidden - plan stands behind the pattern is also intriguing for work on corporate actors. It can already be conjectured by reference to the biological example that a definite answer to this question is not easy to find. Such an answer requires theoretic considerations of possible alternative explanations and, based on these considerations, empirical - in the best case experimental - examinations.

\section{Examples for clear cases of self-organization}

Considering some examples may further clarify our understanding of "emergent patterns" that make a system self-organized. A pertinent example from physics is the Rayleigh-Bénard convection. ${ }^{19}$ Between two rigid horizontal plates, a fluid is heated from a lower plate and cooled from an upper plate. If the difference in the temperature between the two plates is sufficiently large, the fluid begins to flow and the resulting current forms a pattern. The ascending fluid must be replaced by fluid descending somewhere. The resulting current is convection because the current comes along with the transfer of energy - heat energy in this case. Instead of regarding the difference in temperature between the upper and lower plate and describing the convection in connection with this difference, the formal description in physics considers the (marginal) augmentation in temperature in the system divided by the (marginal) change of the difference in temperature between the upper and the lower plate. If this quotient is above a specified value - a threshold - convection begins.

Above this threshold, the theory describes the changes of structures in connection with the distance to this threshold. The amazing thing about self-organizing systems is the non-ambiguous functional relationship between the form of the pattern and this distance. Furthermore, it is stunning that increasing the difference does not merely lead to random patterns in the fluid - i.e. turbulences in the technical sense - but that "complex" patterns can be found, such as the spiral defect chaos. All these cases are structures that can be described with relatively simple deterministic equations, and not with stochastic models as in thermodynamics.

Altogether, there are three different phases. If the difference in temperature is sufficiently small, heat energy is transported without convection, i.e. the fluid remains in a stationary resting state. Above a critical mass, the movement of small rolls - convection rolls - can be observed. The fluid organizes itself in a regular arrangement of small cells (Bénard cells). The rolls alternate to spin right and left successively, similar to intertwining gears. Unpredictable, slight differences in 
the initial conditions effectuate one of the two spins. The system makes a quasi "choice" between two possible states. This is what chaos theory names a "bifurcation" ${ }^{20}$

„Generally we have successive bifurcations when we increase the value of some characteristic parameter [...]. We have a single solution for the value $\lambda_{1}$, but multiple solutions for the value $\lambda_{2}$. It is interesting that bifurcation introduces in a sense "history" into physics. [...] Every description of a system which has bifurcations will imply both deterministic and probabilistic elements.“(Prigogine 1977, p. 272 f.)

The consequence of a further increase in the difference of temperature above a critical mass is a "chaotic" macroscopic state. There, a roll that is being considered spins with irregular velocity for instance, clockwise - and suddenly changes its rotational direction. These abrupt changes are repeated at indeterminate time intervals (with respect to the phases, see also Skirke 2005).

This example makes it clear that, from the point of view of the natural sciences, "selforganization" and "order” do not presume intentionality or intentional systems. It is important to keep this issue in mind with respect to the biological systems that will be presented below. It prevents the misconception that a necessary precondition for self-organization in biological systems is that the individual behave intentionally. Actually, biology ties onto the notions from the hard sciences.

In biology a simple example of self-organizing systems are bark beetles, which build up clusters or colonies under the bark of trees. Experiments in the laboratory have demonstrated that this clustering occurs even if the eggs are randomly distributed. The only precondition is that the density of the eggs (i.e. the number of the eggs divided by the area where they have been deposited) be sufficiently high or, if the density is low, that small clusters can already be found in the initial distribution (a low density corresponds to phase I of the example given above; a high density corresponds to phases II and III). The individual hatched larva emits pheromones that can be perceived by other larvae. The concentration of the pheromone decreases in reference to the distance to the respective larva. Each larva moves to locations with high concentrations of pheromones, i.e. locations where (presumably) many other larvae can be found. If the gradient of pheromone concentration is not sufficiently high in any direction, the larva moves randomly. The larvae orientate themselves to these clusters and thus provide big colonies. Thus, the formation of clusters can be explained by the interplay of two forces. On the one hand, the random movements of the larvae and, on the other hand, the attraction of pheromones for the larvae (cf. Camazine et al. 2001, p. 131). The resulting colonies are not an epiphenomenon, i.e. an emergent pattern without evolutionary importance, but augur evolutionary success:

Although experimental conditions can be contrived in which the larvae do not aggregate [i.e. the case in which there is a low density of eggs M.B.], under normal conditions the larvae almost always operate in a parameter range where strong aggregation occurs. This makes sense, for if this clustered feeding is an important adaptation for countering the tree's defensive production of 
sticky resin, then that clustering is expected to be consistently observed under natural conditions (Camazine, Deneubourg, Franks, Sneyd, Theraulaz und Bonabeau 2001, p. 37).

Hence, emergent patterns can certainly be selected by evolution, but they need not be. The former is the case of an adaptive emergence, the latter of an epiphenomenon. Empirically, is often not (yet) clear which of the cases applies.

\section{Chaos theory ${ }^{21}$}

In the remarks given earlier, it was mentioned several times that chaos is a necessary precondition for self-organization. However, an exact explanation or definition of chaos is still to come. Up to now the concatenation of negative with positive feedback loops has been identified as a necessary precondition for chaos. In this section, an introduction to a mathematical understanding of chaos and chaotic functions will be given, followed by a presentation of the connection to feedback mechanisms with concatenated positive and negative feedback loops.

An important argument for cases where reductionism fails was developed in mathematical chaos theory. This theory yielded a clear-cut distinction between predictability and determinism, which are often understood as synonyms. The mathematical insights into chaos made clear that formal deterministic models are not necessarily non-ambiguously predictable.

This insight is amazing, because, for many centuries, science was dominated by the idea that the future states of the world are determinate and thus, in principle, predictable if we only could completely grasp an actual (in the main physical) state of the world. This belief that the past completely determines the future is often called "Laplace's demon”. Besides Laplace, other famous scientists such as Blaise Pascal and Albert Einstein were convinced of the truth of this belief. The latter trusted that there was a fundamental determinate principle in the world - "God doesn't roll dice" - and due to its confirmations, he believed that with the stochastic models in quantum physics, atomic orbital models would be disavowed as soon as the underlying causalities were identified. Despite his ingenuity, Einstein was mistaken on this issue. ${ }^{22}$ Chaos theory, a relatively new branch in mathematics, identifies a class of functions where minimal deviations in the initial values lead to completely different results. For example, such equation systems are used in meteorology. In 1961, the meteorologist, Lorenz, used such a system to describe weather activities, unaware of the deterministic chaos that was inherent in his model:

One day in the winter of 1961, wanting to examine one sequence at greater length, Lorenz took a shortcut. Instead of starting the whole run over, he started midway

21 This presentation is based on Beckenkamp (1995).

22 "Einstein was very unhappy about this apparent randomness in nature. His views were summed up in his famous phrase, 'God does not play dice'. He seemed to have felt that the uncertainty was only provisional: but that there was an underlying reality, in which particles would have well defined positions and speeds, and would evolve according to deterministic laws, in the spirit of Laplace. This reality might be known to God, but the quantum nature of light would prevent us seeing it, except through a glass darkly” (Hawking 2005). 
through. To give the machine its initial conditions, he typed the numbers straight from the earlier printout. Then he walked down the hall to get away from the noise and drink a cup of coffee. When he returned an hour later, he saw something unexpected... This new run should have exactly duplicated the old... Yet ... Lorenz saw his weather diverging so rapidly from the pattern of the last run that ... all resemblance had disappeared (Gleick 1987, p. 17).

How was this possible?

There had been no malfunction. The problem lay in the numbers he had typed. In the computer's memory, six decimal places were stored: .506127. On the printout to save space, just three appeared: .506. Lorenz had entered the shorter, rounded-off numbers, assuming that the difference - one part in a thousand - was inconsequential (Gleick 1987, p. 17).

The case shows that systems that are described with chaotic equations, and where the parameters of the equations are within a certain range, behave quasi-randomly, although determinism underlies this "random process". Minimal deviations in the initial values may lead to completely different predictions of the system's future behavior. The prediction or result cannot be approximated if we get closer to the "true" initial values.

Dynamic systems can be modeled with mathematical equations giving a unique instruction for the calculation of the progression of the system states such that the trajectory of the system is completely determined by the initial state. Despite this determinacy, in the numerical calculation of the solution curves or in observations in real experiments, the state of the system changes are often extremely complicated, they occur at irregular time intervals, and closely connected initial states lead to completely different states in finite time. In this case, the system or the trajectory is called chaotic (translated from Leven, Koch \& Pompe, 1989, p. 3).

Glancing at the mathematical properties also reveals that the linguistic labeling is slightly exaggerated, because often there is only a constrained value range for the results of the chaotic function - so there is one function that generates the Julia set, another that generates the Feigenbaum set, etc. In other words, even when there are chaotic functional relations, certain results can be excluded in principle. On the other hand, the linguistic label fits rather well to the fact that the sets are uncountable and infinite such that chaotic trajectories do not change in periodical oscillations, and long-term predictions within the value range of these functions are thus prevented. In the following, some formal examples will clarify the respective background.

Chaos theory is relevant in the description dynamic systems with non-linear equation systems. It makes sense to have a short look at linear equation systems before presenting non-linear equations. In doing so, two cases can be distinguished in principle: in the first case, time is a discrete value; in the second case, it is continuous. Such linear systems can be characterized by the following transition functions:

Eq. 1 discrete case: $\quad X_{(t+1)}=c X_{t}$

Eq. 2 continuous case: $\quad \dot{X}_{t}=c X_{t}$ 
The following trajectories can be derived from these equations if the initial state $x_{0}$ is given.

Eql. 3 discrete case: $\quad X_{t}=c^{t} X_{0}$

Eq. 4 continuous case: $x_{t}=e^{c t} x_{0}$

Accordingly, linear systems generate exponential growth. ${ }^{23}$ They are characterized merely by positive feedback loops. There is no negative feedback. Non-linearity is a necessary, yet insufficient, condition for equations that generate chaos. Whether chaos is generated by a nonlinear system depends on the parameter values and the initial conditions. The simplest case of a nonlinear transition function that in principle can generate chaos is a quadratic function. In the continuous case, such a function can model logistic growth, i.e. growth that is limited at the ceiling. The limitation can be interpreted as the capacity of the environment. In analogy to the continuous case, the discrete function is called "logistic mapping” (cf. Leven et al. 1989, p. 13ff.; Schuster 1984, p. 31ff.):

Def. : $x(t+1) \stackrel{\text { def }}{=} f_{r}\left(x_{t}\right)$.

with $\quad f_{r}\left(x_{t}\right) \stackrel{\text { def }}{=} r * x_{t} *\left(1-x_{t}\right) \quad 0<r \leq 4 ; \quad 0 \leq x \leq 1$.

Thus the logistic mapping can represent systems where positive feedback loops are interlinked with negative feedback loops. This family of functions maps $f_{r}:[0,1] \rightarrow[0,1]$. Given an initial value $x_{0} \in[0,1], x_{1}, X_{2}, X_{3}, X_{4}, X_{5} \ldots x_{t}$ can be calculated iteratively. Now, the mathematical analysis of the question whether the function in time approximates a fixed value yields interesting insights. Therefore, we consider the following function $g$ :

$g\left(r, X_{0}\right) \stackrel{\text { def }}{=} \lim _{t \rightarrow \infty} f_{r}\left(x_{t}\right)$

The value $r$ is decisive for the answer. If $r \leq 1$, the fixed value of the function is 0 , i.e. the function is similar to the square root function if you determine the square root of a value and again put this result in the square root function. This can be easily done with a calculator by pushing again and again on the square root function. After enough (recursive) replications, you get the fixed value 1 . In the case of logistic mapping, the fixed value of this recursive procedure is 0 as long as $r \leq 1$.

However, the function g yields completely different results in cases where $r$ is between 1 and 3 . For the following example, we set $r=2$. If the initial value $x_{0}$ is either 0 or 1 , then $x_{t}=0$ for all $t$ $>0$. For any other initial value, the result of function $g$ is 0.5 . Therefore, there are two fixed values for the logistic mapping $f$, the values 0 and 0.5 . If $x_{0}=0$ or $x_{0}=1$, then $\mathrm{f}_{2}\left(\mathrm{x}_{\mathrm{t}}\right)=0$ for all following time points. Any other initial value $x_{0}$ within the permitted range yields:

$\lim _{t \rightarrow \infty} f_{2}\left(x_{t}\right)=0,5 \cdot \lim _{t \rightarrow \infty} f_{2}\left(x_{t}\right)=0,5$.

23 To simplify matters, this paper discusses and analyses one-dimensional systems (i.e. equations with one variable). Analogical conclusions on multidimensional systems are not necessarily logical. 
Thus, in this case, the instable fixed value 0 and the stable fixed value 1 can be found. The former is instable, because it only occurs when $x_{0}=0$ or $x_{0}=1$. If, however, $x_{0}$ is neither 0 nor 1 , with the recursive application of the function, the values converge to the stable fixed value 0.5 . This is even the case if $x_{0}$ only slightly deviates from 0 or from 1 . The dynamic system comes into a stationary state. The numerical properties are visualized in the following figure (adapted from Leven et al. 1989, p. 15). It shows the parabola $\mathrm{f}_{2}(x)=2 * x *(1-x)-($ i.e. $r=2)$ - and the linear function $y=x$.

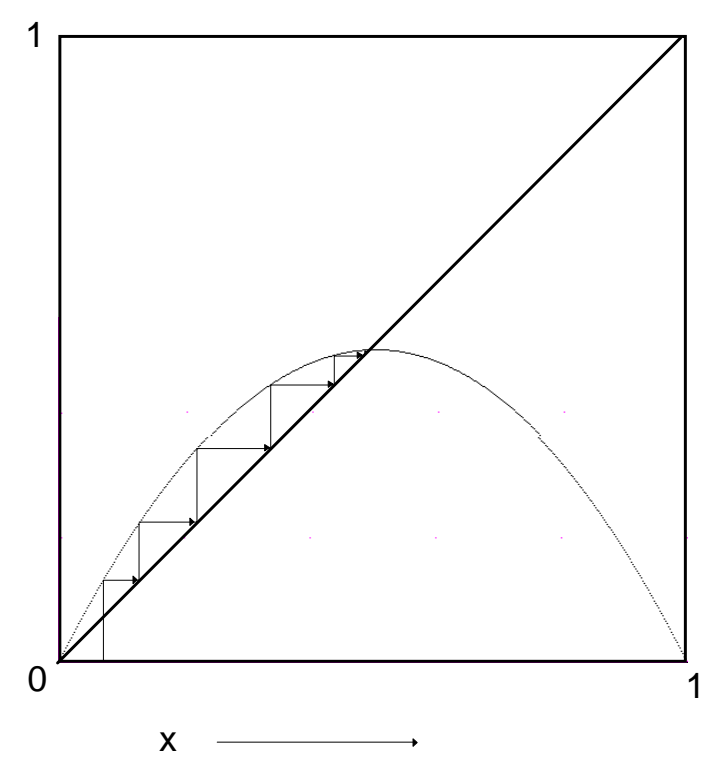

Figure 6: Recursive application of the logistic mapping with $r=2$ und and the initial value $x_{0}=0,1$.

The vertical line up to the parabola corresponds to the repeated input of a calculated value into the function. The result that can be found there (by reading the value on the abscissa) now has to be put into the function again. In the graphical representation, this can be done by drawing a horizontal line from this point to the linear function where $y=x$. The result of the input of that value can be found again by drawing the vertical line up to the parabola, and so on. The graphical representation clearly shows how the recursive application of the logistic mapping with $r=2$ approaches asymptotically to the value 0.5 .

However, such a stable fixed value can only be found as long as the parameter $r$ of the logistic mapping is below the value 3. If $r$ is above this value, then the recursive application of the function yields two results that flip from period to period. This is what mathematicians call a perioddoubling bifurcation (cf. Leven et al. 1989, p. 15). Increasing $r$ yields more and more perioddoubling bifurcations. In other words, after a sufficient number of recursive iterations, the function yields periodic results that repeat in a span of 4, 8, 16, etc. periods if $r$ is increased. So far, this might seem to resemble discrete functions, but if the parameter $r$ surpasses a certain value ( $r \approx 3.57$ ), the system will become aperiodic. In other words, the number of discrete positions now becomes infinite. 
It is when the driving parameter, $r$, is slowly turned up that interesting things happen. When $r=3.0, x_{n}$ no longer converges - it oscillates between two values. This characteristic change in behavior is called a bifurcation. Turn up the driving parameter even further and $x_{n}$ oscillates between not two, but four values. As one continues to increase the driving parameter, xn goes through bifurcations of period eight, then sixteen, then chaos! When the value of the driving parameter $r$ equals $3.57, x_{n}$ neither converges nor oscillates - its value becomes completely random (Bradley 2006; a similar presentation is also given in Leven, Koch, \& Pompe, 1989, p. 15f.).

If $r$ is above this value, values can be found that again lead to periodic results, but so can parameter values that do not create stable periodic solutions. In this case, the system is highly sensitive to the initial values. The system behaves chaotically (cf. Leven et al. 1989, p. 18).

This can be represented graphically in a bifurcation diagram. The following figure was created by a program that, beginning with $r=2.9$ and increasing the values of $r$ with $\Delta r=0,002$, made 300 iterations respectively, and plotted the results in the graphical representation. In order to represent merely the asymptotic behaviour, for each value of $r, 100$ iterations $\left(x_{1} \ldots X_{100}\right)$ were calculated before the points where plotted. The points of period-doubling bifurcations can clearly be seen, as well as the transition into chaos and some periodic "windows" beyond (cf. Figure 7). ${ }^{24}$

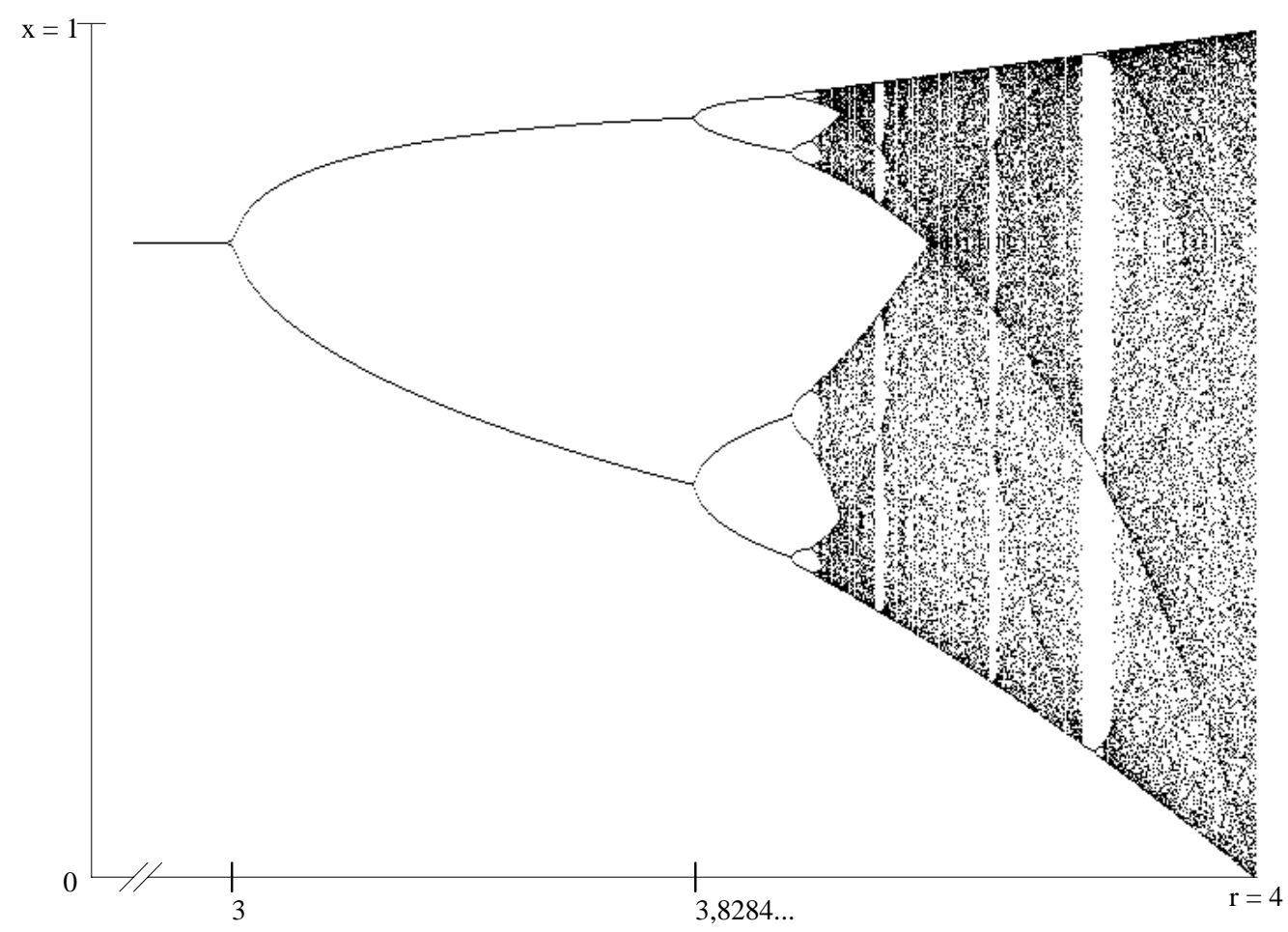

Figure 7: Bifurcation diagram

24 Because the program calculated in this computation has maximally 300 points, in this figure the areas with periods above 300 oscillations cannot be distinguished from chaotic areas. This is a principle problem of precision, resulting from the application of simulations to the visualisation of formalisms. 
Furthermore, the fractal structure of this diagram is interesting. Zooming into branches of the diagram (for instance, the first branch on the top beyond the first window) would yield the same diagram again, although on a much lower scale. From this zoomed in area, it would be possible to zoom in again to the area near a branch, and this zoomed-in view of the area already zoomed into would again yield a similar picture. Theoretically, this could be done ad infinitum. ${ }^{25}$ Beyond formalism, these fractal structures make chaos theory attractive from an aesthetic point of view (cf. Peitgen and Richter 1986). But they also allow us to draft new dimensional models or a new geometry in mathematics. In 1967, Benoit Mandelbrot published "How Long is the Coast of Britain?” in Science. How the length of a coastline is adequately measured seems to be a simple question; however, his answer gave rise to a new geometry, because geographical curves are so involved in detail that their lengths are dependent on the scale of the chosen map: the finer the scale, the longer the coastline. An arbitrary fine scale would yield a coastline of infinite length. ${ }^{26}$ Therefore, the lengths in Euclidean geometry are infinite or undefinable. Mandelbrot's innovative idea consisted in looking for a measure $D$ of the degree of complication (from scale to scale). He showed that this measure has many properties of a "dimension” (cf. also Jürgens et al. 1989, p. 52).

... no real structure can be magnified repeatedly an infinite number of times and still look the same. The principle of self-similarity is nonetheless realized approximately in nature: in coastlines and riverbeds, in cloud formations and trees, in the turbulent flow of liquids and in the hierarchical organization of living systems. It was Benoit B. Mandelbrot who opened our eyes to the fractal geometry of nature (Peitgen and Richter 1986, p. 5).

Let us review the issues that are relevant for the discussion that follows below. There are (dynamic) systems that can be described with nonlinear, recursive equations. Depending on the parameters in these equations, the results (and thus the corresponding systems) may behave chaotically, meaning that marginal deviations in the initial values of these equations (or in the initial conditions of the corresponding systems) yield completely different predictions regarding the behavior in the future.

Although the following claim could be derived from the presentation provided so far, given its relative importance, it will be made explicit: The nature of the predictability problem (or the principle unpredictability) is strictly formal and is independent of any problems regarding the precision of a measurement. Put differently, the unpredictability of chaotic systems would even occur if - in contradiction to Heissenberg's uncertainty principle ${ }^{27}$ - measurements could be effectuaded with arbitrary precision.

Put differently, even without any measurement problems, systems can be unpredictable over the long run. Given a sufficiently long time horizon, chaotic systems are unpredictable in principle if the parameters are within a range that leads to chaos.

25 In this context, the notion of "self-similarity" is used.

26 In a personal notice, Darrell Arnold noticed a nice analogy of this problem to Zeno's paradox.

27 Heisenberg's arguments about a principal uncertainty can be found in Heisenberg, 1983, p. 43f. 
If we were able to precisely determine a variable at time point $t_{0}$, and there was no doubt about the measurement, it would be possible to predict the system condition at time point $t_{1}$ with some accuracy, but the precision of the prediction will have to break off at some point, for instance, at the billionth decimal point; for in the end, in finite time, every calculation of a number with an infinite number of digits in which no continuous pattern or replication occurs must be broken off at some point. Now, however, marginally small deviations in this formal calculation at timepoint $\mathrm{t}_{1}$ - for instance, at the trillionth decimal point - lead to a completely different value for the variables of the system in the later time sequences. Thus the non-predictability is based solely on the formal characteristics of the chaotic system insofar as the variables to be calculated are real numbers - that is, they are in principle able to be provided with an infinite number of decimal points. The problem with the unpredictability of chaotic systems is merely hightened by the Heisenberg uncertainty principle in that now - because of the imprecision of the measurement itself - the problem of predictability occurs at the outset. However, it is not a necessary condition for the unpredictability of chaotic systems.

To sum up again, certain deterministic systems - the chaotic systems - are characterized by the fact that the accumulation of an arbitrary (but countable) amount of information is not sufficient to obtain exact predictions. In chaotic systems, determinism diverges from predictability. The Laplacean demon ${ }^{28}$ is a chimera:

Yet until recently there was little reason to doubt that precise predictability could in principle be achieved. It was assumed that it was only necessary to gather and process a sufficient amount of information. Such a viewpoint has been altered by a striking discovery: simple deterministic systems with only a few elements can generate random behavior. The randomness is fundamental; gathering more information does not make it go away. Randomness generated in this way has come to be called chaos (Crutchfield, Farmer, Packard \& Shaw 1986, p. 46).

\section{Chaos theory und chaotic systems}

Although we have already discussed chaotic systems in the depiction of chaos theory, the equations have not yet been related to the feedback mechanisms, which were earlier identified as an essential characteristic of systems. If a system is described by a chaotic equation such as that in a logistic mapping, then the system inevitably contains at least one positive and one negative feedback loop. In the logistic mapping, the positive feedback is captured with the linear growth component:

$X(t+1)=r * X t$

The negative feedback results from the multiplication of this term with $\left(1-x_{t}\right)$, if, as is the case with the logistic mapping, $x_{t}$ is always a value interval between 0 and 1 . We can now integrate this formal relation into our figure (cp. Figure 4) on population growth:

28 The view of the mathematician, Laplace, that, with knowledge of the place and velocity of all the parts of the universe for a particular time point, the future could be predicted. 


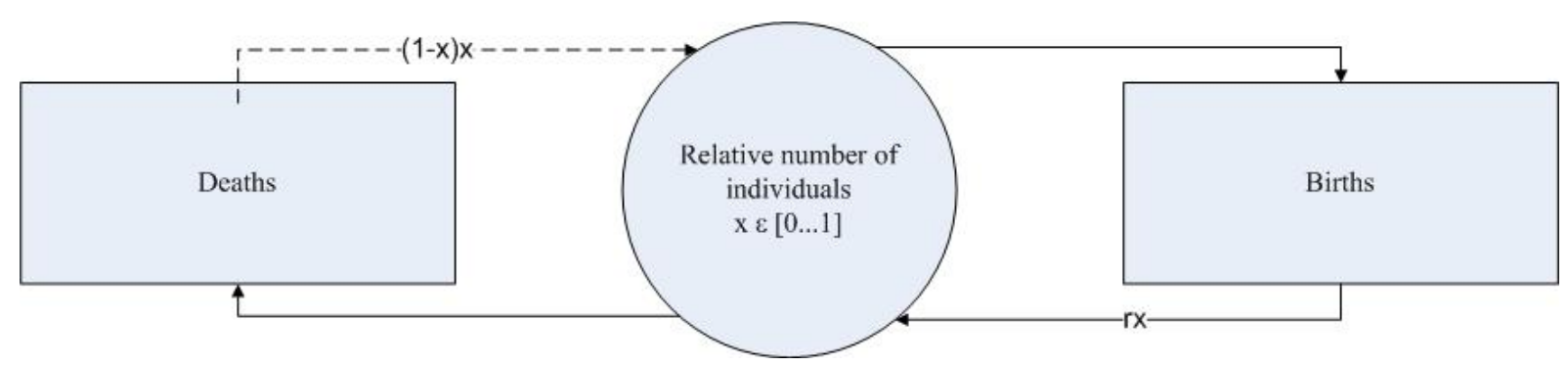

Figure 8: Integration of a chaos-theoretic formula into a system diagram

A cylce in this system begins with a relative number of individuals $x . x=1$ is equivalent to a completely saturated population (i.e. a larger population is not possible); correspondingly, $\mathrm{x}=0$ is an extinct population; and $\mathrm{x}=0.5$ is one-half the size of the maximal possible population. The population of the relative size $\mathrm{x}$ grows at growth factor $\mathrm{r}$ through the system component of births. The resulting $\mathrm{x}$-value is the input parameter for the component of fatalities, and there reduced by the factor (1-x). A complete loop of this model corresponds precisely with the logistic mapping. A new cycle, with a new number of individuals, begins. ${ }^{29}$

\section{About the "complexity" of chaotic systems}

Among other things, chaotic systems possess the following characteristics: on the one hand, their solution paths are unpredictable, but an element of regularity in the apparent "chance" is expressed in the fractal structure (cp. Liening 1999, p. 122f.). Time and again, when arbitrarily zooming into areas of the bifurification diagram (cp. Figure 7), it is possible to identify new bifurification diagrams. Chaotic systems are thus not purely arbitrary, nor are they perfectly ordered. In other words, they are complex. Although the concept of complexity is difficult to get a hold of, it plays an important role in connection with self-organizing systems, which can in principle produce chaotic behavior. Often, though, the explanations of the concept of complexity tend to be confused:

To begin with, the term complex is a relative one. Individual organisms may use relatively simple behavioral rules to generate structures and patterns at the collective level that are relatively more complex than the components and processes from which they emerge [...] [S]ystems are complex not because they involve many behavioral rules and large numbers of different components but because of the nature of the system's global response. Complexity and complex systems, on the other hand, generally refer to a system of interacting units that display global properties not present at the lower level ... Complexity in a system does not require complicated components of numerous complicated rules of interaction (Camazine, Deneubourg, Franks, Sneyd, Theraulaz und Bonabeau 2001, p. 11).

Complexity is a concept that ought to characterize the structural character or order of a system. But why then don't we speak of entropy, as, for example, in thermodynamics, and in so doing 
appropriate the entire calculus that was developed in that context to characterize disorder, or the measure developed by Shannon in information theory for determing the content of information possessed by a new unit in an information flow? Here, when there is complete information, every further unit of information is predictable; the information content in this case is 0 . The unit is not needed to eliminate the insecurity about the factually existing relationships. If, however, we have completely uncorrelated units of information, then the acquired information about every single unity has a maximal value of 1 . In a world of pure chance and completely independent events, any further information is relevant (cp. Attneave 1969).

This information-theoretic view of order (or disorder) is only of limited use; for in referring to the order, structure or complexity of systems, we mean something different from what we mean in characterizing "order" in entropy or information theory: The amount of Shannon information is inversely related to the probability of the occurrence of an event. This, however, stands in a contradiction to our intuitive notion of structure, which entails something between perfect order and randomness. Comparing a black screen with a screen with white noise yields no difference with respect to the intuitive notion of complexity (cf. Fellermann 2003, p. 29).

However, the degree of information of any pixel of the the black screen is 1 (i.e. each pixel yields the complete information about the screen), whereas the degree of information of a pixel in the white noise is 0 (for complete entropy). Neither condition is "complex". Systems are especially complex if they move in the area between complete predictability and complete unpredictability. The concept of complexity is thus closely connected to the concept of freedom: neither purely chance behavior nor purely predictable behavior is free, whereby, in everyday language, we would refer to behavior as "free" that, on the one hand, fits a provided structure, while, on the other, is not determined by that structure. However, it is difficult to specify the concept, and we are far from possessing “the” measure for complexity (cp. Fellermann 2003).

\section{On self-reference and recursion}

We now know the sufficient conditions that enable a system to generate self-organized structures. These require neither symbolic communication nor symbolic self-reflectivity. In much natural scientific work on self-organizing systems, such as Prigogine's, one thus does not find the expression "self-reference", while one does, however, in the radical constructivism of Varela and Maturana, as well as the sociological system theory of Niklas Luhmann. The latter even treats the two terms as synonyms (cf. Luhmann1994, p. 57).

At the same time, Luhmann recognizes the "classical site" of the concept in human consciousness, but he detaches it from that context and transfers it to real systems. This conception, too, can only be partially understood from a natural science perspective - if that natural science perspective does not claim to be a radical constructivist one - although in the following it will become clear that conceptual relationships exist between feedback, (self-)reference and recursion. 
From the perspective of the symbol processing appraoch in cognitive science, as well as the perspectives of physical system theory and Quine's analytical philosophy (for all three approaches, compare, for instance, the descriptions in Hofstadter 1985), the concept of self-reference is not necessarily system theoretic in nature; rather, it is related to the character of symbols, calculus or formal languages. A symbol or a chain of symbols can be cited and thus become an object of a longer symbolic expression. Self-reference forms a special case of reference in the sense of Gottlob Frege ${ }^{30}$ (1983 - origninally published in 1892). Self-reference is recursion in logical sentences. An example from Hofstadter and Dennet (1981) may illustrate this:

'Thiss sentence contains threee errors'. On reading it, one’s first reaction is, 'No, no, - it contains two errors. Whoever wrote the sentence can't count.' At this point, some readers simply walk away scratching their heads and wondering why anyone would write such a pointless, false remark. Other readers make a connection between the sentence's apparent falsity and its message. They think to themselves, 'Oh, it made a third error, after all - namely, in counting its own errors.' A second or two later, these readers do a double-take, when they realize that if you look at it that way, it seems to have correctly counted its errors, and is thus not false, hence containing only two errors, and ... 'But ... wait a minute Hey! Hmm ...' The mind flips back and forth a few times and savors the bizarre sensation of a sentence undermining itself by means of an interlevel contradiction - yet before long it tires of the confusion and jumps out of the loop into contemplation, possibly on the purpose or interest of the idea, possibly on the cause or resolution of the paradox, possibly simply to another topic entirely (Hofstadter und Dennett 2000, p. 276f.).

At the same time, this example illustrates that, beyond reference and self-reference, this opens the possibility to produce paradoxes, such as in the sentence "This sentence is false" or "Martin Beckenkamp always lies.” Self-reference, as the word indicates, exists when a linguistic expression, e.g. a sentence or a predicate, refers to itself. An example is:

This sentence is short.

Here, it is said that a certain sentence is short, and indeed the very same sentence in which the statement is made.

Self-reference need not result from a direct reference to itself; it can also be generated from several intermediate steps:

The following sentence is true.

The previous sentence is not true.

The self-reference in the previous examples was able to be produced with the demonstrative pronoun "this" or "the following" or "the previous sentence", that is, with the linguistic pointing function (Deixis), which, more or less like a pointing finger, indicates that the reader should look

30 What nowadays, in the context of analytical philosophy, is named "reference” was named "meaning” (in German "Bedeutung”) in Frege's terminology. The current notion of “meaning” corresponds to Frege’s term “sense” (in German “Sinn”). 
here or there. Besides this, there is also the possibility to produce self-reference with a citation construction, as, for example, in

"X is false if it is repeated”, whereby $\mathrm{X}$ is a placeholder (variable) for an arbitrary linguistic expression. If one inserts "is false if it is repeated" for $\mathrm{X}$, a self-referent sentence results, and a paradox:

“'Is false if it is repeated' is false if it is repeated."

Through the proof that it is possible to represent arbitrary logical expression in what is known as Gödel numbering, and also to express self-reference in mathematical calculus in this way, the mathematician, Gödel, was able to prove the impossibility of a complete and noncontradictory (consistent) mathematics (cp., for example, Hofstadter 1985). This reference should suffice to highlight the significane of the concept of self-reference even outside its system-theoretic embeddedness in formal sciences oriented around mathematics.

Similarly important for mathematics and the natural sciences oriented on mathematics is the concept of recursion. This concept specifies a function's or a procedure's appeal to itself. To prevent the recursion from leading to an infinite regress and to ensure that a calculation can be brought to an end, it is necessary to achor the recursion. It is thus possible, for example, to define the factoral of a number $n$ ! of an arbitrary natural number $n$ as follows:

$0 !=1$

$\mathrm{n} !=\mathrm{n}((\mathrm{n}-1) !)$

To calculate the expression 3! in accord with this recursive definition, the following is done:

$3 !=3 *(2 !)=3 * 2 *(1 !)=3 * 2 * 1 *(0 !)=3 * 2 * 1 * 1=6$

The recursion could be calculated by providing the result of the calculation for the number 0 directly, and, technically speaking, the function calls on itself until it is possible to replace 0 ! with the result 1 , and then to calculate the entire term by a concatenation of the intermediate results. This example also highlights the conceptual relationship between the self-reference of functions and procedures.

System theory is not a computatbility theory, but here too, the concept of recursion is used. In the illustration of the logical figure, it was shown that the result of a function can once again be used as an input value for a further calculation of one and the same function. This, however, distinguishes the recursion. In the system-theoretic version, however, the recursion is not anchored because, in principle, a potentially infinitely long-running system does not entail any theoretical problems. It thus makes sense that many system-theoretic illustrations use the concepts of recursion, iteration and feedback synonomously (for example, see Liening 1999, p. 123). 


\section{Stigmergy}

On the other hand, in system-theoretic views of biology there are conceptual refinements to differentiate feedback from signals from feedback from cues.

Interactions with self-organized systems are based both on signals and cues. But whereas information transfer via signals tends to be conspicuous, since natural selection has shaped signals to be strong and effective displays, information transfer via cues is often more subtle and based on incidental stimuli in an organism's social environment (Seeley 1989b). The lack of prominence of cues means that many interactions within animal groups are easily overlooked, a fact that contributes to the seemingly mysterious origins of the emergent properties of self-organized groups (Camazine, Deneubourg, Franks, Sneyd, Theraulaz und Bonabeau 2001, p. 21).

While signals are used for an intended communication between one individual agent (such as, for example, an ant) and another, cues are conveyed through a change in the environment, which does not primarily have a communicative purpose. Here, the changed environment gives the relevant stimulus for carrying out the suitable behavioral program. In such cases, biologists speak of stigmergy (meaning something like “a process in motion”):

Information acquired directly from other individuals is only one source of information used by organisms in self-organizing systems. In situations where many individuals contribute to a collective effort, such as a colony of termites building a nest, stimuli provided by the emerging structure itself can be a rich source of information for the individual ... In the study of social insects, the term stigmergy (Grassé 1959 1967) has been used to describe such recursive building activity (Camazine, Deneubourg, Franks, Sneyd, Theraulaz und Bonabeau 2001, p. 23).

Combinations of environmental changes with signals are possible. Termites, for example, mark their rock clots when building pillars with pheromone so that the pillars, which are sensitive to building, manifest both a change in size and a change in the concentration of the pheromone.

Here, qualitative stigmergy differs from quantitative stigmergy (also as sematectonic and signbased stigmergy; cf. Brückner 2000, p. 13). Sematectonic stigmergy is evident in ants, for example, when dead ants are deposited on hills. It can be modeled with the following algorithm:

Rule (1).- - Move randomly over the field.

Rule (2).- - If you find a dead ant at point $\mathrm{x}$ in the field and if you [are not carrying already one], then pick it up with a probability $\mathrm{P}_{\mathrm{up}}(\mathrm{f}(\mathrm{x}))$.

Rule (3).-- If you [are carrying] a dead ant, then drop it with a probability $\mathrm{P}_{\text {down }}(\mathrm{f}(\mathrm{x}))$. The probabilities $\mathrm{P}_{\text {up }}$ and $\mathrm{P}_{\text {down }}$ depend on the density $\mathrm{f}(\mathrm{x})$ of dead ants in the vicinity of location $\mathrm{x}$. An ant perceives the density by keeping a short-term memory of the number of dead ants encountered in its random walk. The higher the density of dead ants, the lower is $\mathrm{P}_{\text {up }}$ and the higher is $\mathrm{P}_{\text {down }}$

(Brückner 2000, p. 13 - slight linguistic modifications of the citations are given in brackets).

Sign-based stigmergy is used by ants, for example, to construct ant trails. Imagine that a straight connecting line from nest A to a rich feeding source B is interrupted. Initially, the ants have the same probability of going to the right and to the left to get around the hinderance; in doing so, 
though, they always leave a trace of pheromone behind them. As a result, it will not take long for the ant colony to find the shortest way: given the shorter distance will be traveled more often, the concentration of pheromone in that area will be higher, and more and more ants will take the right trail.
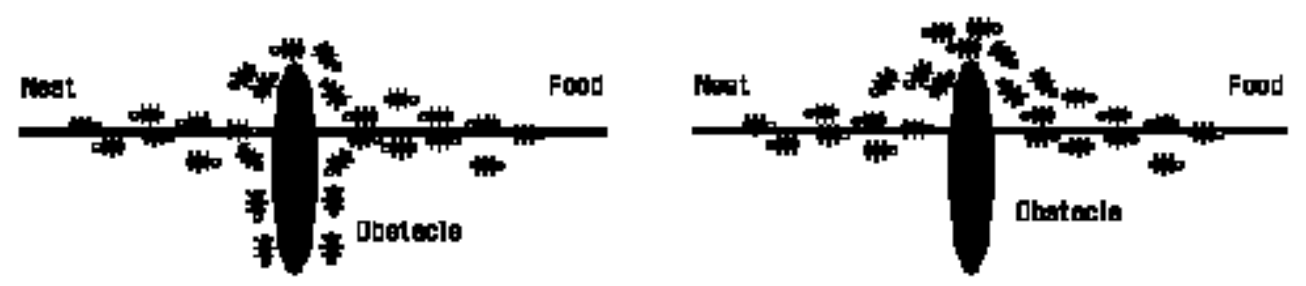

Figure 9: The construction of the optimal ant trail to the feeding source (from Brückner 2000)

Ants use different pheromones for different purposes, normally between 10 and 20, in order to signal something like "searching for food", "this way to the food”, "alarm, run away", or "we must carry the dead ants away” (cp. Johnson 2001, p. 75).

\section{Summary}

The goal of the presentation so far has been to offer reasons for viewing collective actors from a macro-perspective. The basis has now been laid so that we can again turn to the question of collective actors. The argumentation in the first part of the article is that a holistic perspective is not necessarily provisional, just to be held until we possess sufficient knowledge necessary for us to completely transfer to a detailed reductionist model. In other words: The aggregate of individual bits of information can have a quality of its own. Individual bits of information and aggregates are not able to be exchanged for one another without a loss of quality. Often a holistic perspective is taken as a research stategy because, for example, not enough information is available at the micro-level. This is something of an aggregate "on loan”, which is later to be exchanged for the hard currency of microfoundational knowledge, something like the way that Mendel's genetics is now understood as as a DNS sequence, while it was viewed at his time as purely functional because the corresponding micro-biological knowledge was lacking (cp. Wiesendanger 1987). By contrast, holistic models, i.e. models in which many parts are commonly integrated into multinary relations (like trinary or quadrinary relations), possess an explanatory quality of their own. Furthermore, it was shown that deterministic models in principle can be nonpredictable if determinism generates mathematical chaos. Therefore, a subset of systems with positive and negative feedback can only be predicted in its systemic form and it is not reducable to its components without a loss of predictability. Such systems have the potential to generate self-organization and emergence so that the parts no longer just determine the whole, but the whole determines the parts in ways that are just as important.

This work has also shown that the concept of self-organization can be misleading because the quality by no means presupposes intentionality or the ability to process symbols, but can be ob- 
served in pure physical systems. The possibility of utilizing signal information and information on environmental changes broadens the scope of biological systems: there we find, for example, throngs of self-organizing systems. And it is by no means metaphorical to speak about the behavior of ant colonies, bee colonies or schools of fish. Harvester ants form their dumps as far as possible from their graves, create trails and are able to erect structured housing without a central plan and without a regent: There is indeed a queen. She, though, does not "govern", but spends her time laying eggs. She does not provide a plan or make a central "navagational map" or "developmental plan” available (cp. the work of Deborah Gordon in Johnson 2001). The colony, swarm, or school is intelligent, but not the individual ant, bee or fish:

In recent years swarm intelligence has gained increasing popularity. Swarm intelligence is broadly defined as follows: 'Any attempt to design algorithms or distributed problem-solving devices inspired by the collective behavior of social insect colonies and other animal societies’ [Bonabeau et al. 1999] in Brückner (2000, p. 12)-

\section{What are self-organizing systems?}

Self-organizing systems are systems in which an emergent pattern arises from the interaction of many individual parts of the system, which, for their part, just react to one another locally. These patterns are ordered and suggest that there is a central program or a central plan (as, for instance, DNS) or that a central command is present in which all the elements are joined together and the whole is coordinated. The special thing about self-organizing systems is that they possess no central authority (pattern specification, collective program, command, central plan), but the individual actors of the system create something collectively without "knowing" in the last analysis what this "something" will be or what shape it will have. In other words, in this case, the individual has no information about the resulting collective structure.

\section{Which concepts were not discussed?}

Various concepts from Luhmann's systems theory, which adapted these from radical constructivism, have not been discussed here: autopoeisis, variability and "Leitdifferenz". The goal of this work has been to provide reasons for adopting the macro-perspective when evaluating collective actors. These reasons could also be viewed as a checklist that makes it possible to assess whether a macroscopic view can lead to new insights, which do not result from methodological individualism. Luhmann, by contrast, presumes this macroscopic view and develops - more or less in isolation - his theoretic cognitive framework.

\section{The Role of intentions for collective actors}

A bunch of arguments and criteria are now available to allow us to speak in good conscience of collective actors as collective actors - with one drawback. All of the examples mentioned so far are collective actors consisting of parts that merely follow laws of nature (Bénard-convection) or relative simple behavioral rules or behavioral programs (ant colonies, schools of fish). Biological 
systsems are considerably more formidable than the self-organizing processes of physicalchemical systems:

The mechanisms of self-organization in biological systems differ from those in physical systems in two basic ways. The first is the greater complexity of the subunits in biological systems. The interacting subunits in physical systems are inanimate objects such as grains or sand or chemical reactants. [...] The second difference concerns the nature of the rules governing interactions among system components. In chemical and physical systems, pattern is created through interactions based solely on physical laws. [...] Of course, biological systems obey the laws of physics, but in addition to these laws the physiological and behavioral interactions among the living components are influenced by the genetically controlled properties of the components. In particular, the subunits in biological systems acquire information about the local properties of the system and behave according to particular genetic programs that have been subjected to natural selection. This adds an extra dimension to self-organization in biological systems, because in these systems selection can finely tune the rules of interaction. By tuning the rules, selection shapes the patterns that are formed and thus the product of group activity can be adaptive (Camazine, Deneubourg, Franks, Sneyd, Theraulaz und Bonabeau 2001, p. 12f.).

It is thus even more baffling that it is possible to identify the very same principles in living and non-living nature. But can principles of self-organization also be generalized to human masses or human colonies? People are intelligent and intentional; they can recognize the intentions of others; they are not just dependent on the use of signals; they are aware of themselves and reflect on themselves. Might these important characteristics mean that the self-organizing process in human collectives is more the exception than the rule? Or, despite these abilities, do we find structured behavior here too that no one provides and that is not intended in any preformulated program? The answer to the problem posed in introduction is difficult: Is the behavior of Deutsche Bank to be understood as the behavior of a collective actor, or is everything essential explained when we refer to Mr. Ackermann's intention and information? Against the background of this issue, we might wonder whether we can view human masses as collective actors at all. At the outset, we must admit that the opening question will not be answered yet, because we do not yet have the right tools. In what follows, however, it should be shown that there has been progress in the recent development of research methods and applications so that it is possible to say in good conscience that, for some collective actors, self-organization and emergence offer additional explanatory power. It is still to be shown how the ideas presented so far are incorporated into economic experiments and analysis regarding public goods and how they can lead to new insights there.

\section{Emergence among groups of human actors}

Self-organization theories are applied to human groups in various areas. Masses are a classical example, for instance, in studies of emergent walkways, the clapping behavior at the opera, the unconscious synchronization of people in patterns of movement, etc. Here, there is a similarity to 
biological systems; for human actors, too, the insights gained so far can be helpful and can offer a sensible framework for a sensible macroscopisc view of collective actors as a whole. Thus, for example, in Krugmans' economic models for urban planning and urban diversification, once again one finds precisely those characteristics that were developed earlier:

A remarkably simple mathematical model that can account for the 'polycentric, plumpudding pattern of the modern metropolis'. Building on the game-theory models that Thomas Schelling developed to explain how segregated cities can form, Krugman's system assumes a simplified city made up only of businesses, each of which makes a decision about where to locate itself based on the location of other businesses. Some centripetal forces draw businesses closer to one another (because firms may want to share a customer base or other local services), and some centrifugal forces drive businesses father apart (because firms compete for labor, land, and in some cases customers). Within that environment, Krugman's model relies on two primary axioms:

1. There must be a tension between centripetal and centrifugal forces, with neither too strong.

2. The range of centripetal forces must be shorter than that of the centrifugal forces: business must like to have other business nearby, but dislike having them a little way away (A specialty store likes it when other stores move into its shopping mall, because they pull in more potential customers; it does not like it when stores move into a rival mall ten miles away) (Johnson 2001, p. 89f.).

Sales people certainly act intentionally and communicate, for instance, passively by reading newspapers or actively by exchanging information with one another. For all that, simple rules that couple positive and negative feedback or centripetal and centrifugal force suffice in Krugman's model - rules that also allow us to describe principles of the self-organization of simple physical and biological systsems:

Even these simple models suggest many of the typical features of economic geography. A far from exclusive list would surely include the following three points:

1. Self-organization: atomistic interactions among individual agents can spontaneously generate large-scale order.

2. Path dependence: small differences in initial conditions can have large effects on long-run outcomes

3. Discontinuous change: small quantitative changes in the underlying factors that drive location will sometimes produce large, qualitative changes in behaviour.

(Krugman 2004, p. 132)

Concentrating too much on the central plans and intentions may distort the view that Krugman opens up with his models on economic-geographical diversification: Here, there is no local plan, no central committee that decides on economic areas and so on. And yet, the model describes the emergence of special structures very well. In his model, Krugmann can also explain the abrupt changes that occur if parameters fall short of or surpass a critical mass. The system has long seemed to act more or less parallel to the changes in the parameters until a bifurcation results and, all at once, the changes become dramatic, just as in biological systems:

A striking feature of self-organized systems is the occurrence of a bifurcation - a sudden transition from one pattern to another following even a small change in a parameter of the system. One speaks of "tuning" a parameter in the system to invoke 
the onset of a different pattern [...] By making small adjustments in such parameters, one can induce large changes in the state of the system, since the system may now be on a trajectory that flows to a quite different attractor. Most self-organized systems have many tunable parameters (Camazine, Deneubourg, Franks, Sneyd, Theraulaz und Bonabeau 2001, p. 32).

In Krugman’s “base-multiplier” model, for example, the aggregate income erratically increases as soon as a critical export mass is suprassed, and, by contrast, the aggregate income plummets as soon as another critical mass is surpassed (cp. Krugman 2004, p. 132).

As an example of a surprising ordering of diversification in otherwise completely unacceptable conditions, Johnson (2001) mentions the boom in Manchester in the second half of the $19^{\text {th }}$ century. Here, among other things, he refers to the descriptions from Friedrich Engels:

The town itself is peculiarly built, so that someone can live in it for years and travel into it and out of it daily without ever coming into contact with a working-class quarter or even with workers .... I have never elsewhere seen a concealment of such fine sensibility of everything that might offend the eyes and nerves of the middle classes. And yet it is precisely Manchester that has been built less according to a plan and less within the regulations of official regulations (Engels 1892, p. 280, cited in Johnson 2001, p. 36f.).

According to Johnson, during the industrial revolution, Manchester grew like cancerous cells, without central planning; yet, stuctures (forms of diversification) can be observed which look like the bourgoise planned it from the outset. They can take the main streets through the entire city without being confronted with the poverty of the working class.

Johnson's example suggests it. Krugman's model explains it with formal precision: Despite all intentionality and symbolic processing, in large enough numbers, people can also be collective actors - a human colony or a human swarm with its own respective logic. They can generate emergence - ordered patterns which no one intended or planned in this form.

But Johnson's example of Manchester also shows that there are good reasons for developmental plans and centeral coordination sites, precisely to avoid the kinds of growths that were able to be seen in $19^{\text {th }}$ century Manchester. Emergence does not appear to be a good solution when it is important, for example, to prevent epidemics or to secure the quality of life in a city. The ability to plan, to generate, to carry out plans, to coordinate action, to use natural and formal languages, and to continue to learn new things and repackage them in new conceptual forms makes it possible to integrate people in collective action top-down or bottom-up in a way not possible in the biological models of self-organization and emergence. Methodologically, biology has a tough time deciding whether it is dealing with a central plan or a central pattern, for example, regarding the question whether the differentiation of the various "roles" can be explained by means of principles of self-organization:

In some cases, however, the colony [of bees] produces multiple swarms. What is responsible for these different swarming responses? Rather than assuming that different behavioral rules determine the type of swarming outcome, let us suppose that the bees respond with the same set of behavioral rules to slightly different circumstances 
such as the initial colony size. In such a system, there may be an economy of behavioral complexity at the individual level required to switch from one kind of behavior to another. Thus, tunable parameters and bifurcations might provide an efficient mechanism for producing flexibility in biological systems ... Their [Deneubourg et al. (1989)] striking finding was that distinct morphological patterns of army ant raids emerged merely by varying the initial distribution of food in the environment [...] We suggest that certain species-specific patterns may be self-organized expressions of differences in environmental variables [...] differences in the raiding patterns of Eciton burchelli versus E. rapax may also reflect genetically based differences in pheromones or behaviors. Undeniably, such differences in biological parameters probably exist, but a remarkable fact is that models of the raiding patterns demonstrate that differences between species in raiding patterns could arise simply from differences in the spatial distribution of each species' prey (Camazine, Deneubourg, Franks, Sneyd, Theraulaz und Bonabeau 2001, p. 36f.).

If this behavior is compared to the behavior of a construction site, then it is clear that such differentiations there can hardly be explained by the current context. The mason is at his site because, within the framework of the plan, the foreman needs him there at a given time.

Central planning and management processes should guarantee that desired emergence becomes hard cast, while countermeasures are taken to control undesired emergence. In such cases the managers react and not the collective actor. ${ }^{31}$ Everyone acts in accordance with the central development plan, coordination plan or strategy. It is thus difficult to decide when a corporate actor is a collective actor. But one thing should not be overlooked here: there are institutional frameworks that are conceived with a view to the expected emergence. One of the most important institutions of this sort is the market.

\section{The market: A collective actor}

In fact, there are good reasons for viewing the market as a collective actor, although it is a manmade and planned institution in which people intentionally act with one another:

The idea that a large collection of interacting objects can produce behaviour at the aggregate level which could not be thought of as corresponding to some blown up version of individual behaviour is far from new. What is newer is the idea that such systems may tend to organize themselves, and, perhaps more, that there may be common features of that behaviour in many, apparently very different types of systems (Kirman 1998, p. 13).

Kirman shows that von Hayek's ideas about emergence are similar to modern interpretations of the self-organization of markets. If we take this thesis seriously, then - similarly to the earlier mentioned examples from biology - it is important to study two issues: 
There are two essential things to examine: how the organisation of the interaction between the individuals and the component parts of the system affects aggregate behaviour and how that organisation itself appears (Kirman 1998, p. 14).

Kirman is quite aware that this interpretation stands in crass contradiction to mainstream economics, which, in its formal models, is strongly oriented on static physics, and consequently essentially sets itself the (difficult) task of analysing equilibrium. By contrast, Kirman's view of markets in accord with principles of self-organization requires that the organization structure of the market interaction be taken into purview and it is seen that the limitations adaptations are mutually beneficial. According to his interpretation, participants in the market do not only learn to adapt to the limitations of the market, but the adaptations themselves lead to modifications in the limitations. Market models that consider such issues do not focus on the formation of market prices, but on the formation of various action strategies, both by the buyers and the sellers, such as the regular customer and the spot buyer:

In an extension to Vriend's original model, Kirman and Friend (1996) considered individuals who make more than one encounter in a trading day. Sellers now set prices they charge to each of their customers and allow the latter to choose whether to accept or refuse these prices. Here the number of rules to choose from is vastly greater than in the original model and poses considerable problems of the type already mentioned, if only for computational reasons. Nevertheless, individual buyers in the model soon learn which prices to accept and which to reject. Furthermore, sellers start to discriminate between buyers and charge their loyal customers different prices than those set to "searchers". Interestingly, some sellers set high prices to buyers and give them priority when there is insufficient stock to serve all the customers. Others do the opposite, giving low prices to loyal customers but serving searchers first at high prices. Although the former strategy yields higher profits, individuals who adopt the low price strategy for their loyal customers get "locked in" and are unable to learn their way to the alternative strategy. Thus a "dominated" type of behaviour coexists with a superior one. The outcome of the process through which the market organises itself would have been impossible to predict by looking at the individual decisions (Kirman 1998, p. 40).

\section{Integration of self-organization in institutional design}

In computer science, approaches emphasizing decentral management systems, which are based on principles of self-organization, are also increasingly popular. The annual robot football championship (RoboCup), an academic conference that has taken place annually since 1993, aims at the development of robot engineering, sensor technology, the processing of spatial information and so on, but also at the improvement of our understanding of the coordinated action of autonomously acting agents without a central plan. With the holonic approach (based on Arthur Koestler's concept of the "holon"), computer science has begun to make use of concepts of selforganization for planning systems, production systems and management systems. 
The application of the holonic concept to the manufacturing domain is expected to yield systems of autonomous, cooperating entities that self-organize to achieve the current production goals. Such systems meet the requirements of tomorrow's manufacturing control systems (Brückner 2000, p. 22).

This interest within the framework of production and planning systems might at first seem perplexing. But here too important pragmatic criteria may play a role; for it is diffult to centrally plan and coordinate the activity of many actors:

A reasonable suggestion is that pattern formation by cooperative groups usually arises through self-organization rather than external guidance because the latter mechanisms generally are exceedingly difficult to implement. This seems especially true for pattern-formation by large groups. For large groups the high complexity and large scale of pattern-formation makes it virtually impossible for a leader to provide group members with detailed building instructions, leaves blueprints an insufficient source of instructions, renders fixed recipes of behavior inappropriate for flexible building behavior that is required, and makes the occurrence of naturally occurring templates highly unlikely (Camazine, Deneubourg, Franks, Sneyd, Theraulaz und Bonabeau 2001, p. 67).

A functioning market - this at least is the view of most economists - performs these tasks with impressive efficiency. Kirman thinks that self-organizing principles of the market are one reason for this, and that this is widely ignored.

The use of the principle of self-organization and emergence in institutional design thus appears at least to be possible, and perhaps even especially promising. Perhaps this aspect has simply been overlooked in other institutions, and this work can contribute to bringing it into purview. Perhaps institutions can be considerably improved if considerations of self-organization and emergence are integrated into the design itself. There are, in any case, examples of this. It is no accident that fluid mechanics research is used for the design of escape routes to prevent panic. These are to be designed so that each individual can act in accord with the simplest rules ("follow the green pictogram”) and so that "turbulences” do not occur when individuals meet, but a steady, quick stream emerges that saves lives (cp. Beckenkamp 2005).

\section{Corporate actors: Emergent and self-organizing?}

The arguments and instruments presented above open up new possibilites for the theoretical and empirical analysis of corporate actors, but also for the design of institutions. Although it is still a hard nut to crack, we have now some more specified criteria that ameliorate the answer to the question whether a specific large group of people, such as an organization or a movement (the labor movement, environmental movement, women's movement) is a collective or corporate actor. 


\section{Tentative criteria}

A first assessment criterion arises from examining the relational network of the actors: Who communicates with whom? Who sanctions whom? ${ }^{32}$ Who trades with whom? Who is responsible to whom or who has authority over whom, etc.? If we find higher digit relations in the relational network, which integrate or interweave a higher number of actors with each other, then a reductionist view in which only individual actors in their one-to-one interactions with each other, or their dyads, are taken into consideration results in a loss of information. So here a holistic view is significant, and makes sense. Soldiers who mutually observe each other's "cowardace in the face of the enemy" form the collective actor, the "troop", as a result of the relational network, in which they are continually under each other's scrutiny and are threatened with the sanction of death. The soldiers in the First World War, described in Axelrod (1984), who simply ignored this mutual control and merely faked battle with their opponents, suspended the battle. The example shows that individuals within a collective actor may have some scope for action, which, if tapped, may lead to the dissolution of the collective actor as collective actor. In other words, the intentionally directed behavior of individuals can dissolve a collective actor. ${ }^{33}$ But whether such a scope for action exists - whether intentions can thus be converted into concrete actions - is related to a question that cannot be answered with the instruments developed here. In any case, if such a scope for action is not tapped by the actors - and this is by no means rare - then it makes sense to focus on the collective or corporate actor.

Collective actors exist if the participating individuals are integrated into a dense relational network. However, if that relational network essentially consists of dyads, this still does not necessarily mean that there is no collective actor; for from a system-theoretic perspective, feedback may be able to be identified. If this results in a structure consisting of positive and negative feedback loops, then, within the collective, self-organization is at least possible. Now it is important to determine whether individual actors act according to a central plan or a central command, or whether they create collective patterns not provided by a central plan or a central model. Here, too, the collective or corporate actors as such are acting and not "only" the participating individuals.

The considerations presented here open up new possibilities for approaching the question of collective actors, which probably will lead to innovative and startling answers. In a recent book, Elinor Ostrom argues that the behavior of individuals in institutions takes place in a framework composed of nested sets of universal components (cf. Ostrom 2005 p. 5ff). This is why explanations occur at different levels, and the "relevant concepts needed to understand phenomena at one level do not necessarily scale up or down” (Ostrom 2005 p. 12). She argues that the chief challenge is to work out what the relevant level of analysis is for a particular question and how to

32 The design of control mechanisms and sancitioning is an important issue in institutional design and are pivotal determinants in neo-institutional economics (cf. Voigt 2002).

33 In a personal comment, Darrell Annold rightly pointed out that it might well be that this could lead to a new emergence of a collective actor with different qualties. Nevertheless, in this example the intentionality destroys a collective actor in a first step. However, this should not lead to the conclusion that intentionality forecloses the emergence of other collective actors. 
focus on actors at the level above and the level below which affect the particular level in consideration. Therefore, there is a high concordance between her view and the view of the present paper. However, whereas her book mainly presupposes the existence of holons and concentrates extensively on issues of institutional analysis, the present paper focused on arguments that allow the conceptual introduction of holons that are independent entities in their own - although they have been derived from a lower level. Therefore, the present paper can also be understood as a complement to Elinor Ostroms reflections, which could enrich the methods that she discusses in her book and bing new insights in the analysis of collective actors and in the understanding of institutions. 


\section{Literature}

Albers, G. (2005). Strukturbildung in der Natur und im Labor. Retrieved 13.4.2006, from http://www.nls.physics.ucsb.edu/papers/Ah98_OvG.pdf.

Attneave, F. (1969). Informationstheorie in der Psychologie. Bern: Verlag Hans Huber.

Audi, R. (Ed.). (1999). The Cambridge dictionary of philosophy. Cambridge: Cambridge Univ. Press.

Axelrod, R. (1984). The Evolution of Cooperation. New York: Basic Books.

Beckenkamp, M. (2005). Institutionelle Ergonomie: Verhaltensrelevante Variablen zur Beeinflussung kooperativen Verhaltens in sozialen Dilemmata. In J. Oebbecke (Ed.), Nichtnormative Steuerung in dezentralen Systemen (Vol. 7, pp. 303-346). Neuhardenberg: Franz Steiner Verlag Stuttgart.

Beckenkamp, M. K. (1995). Wissenspsychologie: Zur Methodologie kognitionswissenschaftlicher Ansätze. Heidelberg: Asanger.

Bradley, L. D. (2006). Logistic Equation. Retrieved 5.4.2006, from http://www.pha.jhu.edu/ ldb/seminar/logdiffeqn.html.

Brückner, S. (2000). Return from the ant: synthetic ecosystems for manufacturing control. Humboldt-Universität, Berlin. (online at http://edoc.hu-berlin.de/dissertationen/brueckner-sven2000-06-21/PDF/Brueckner.pdf).

Camazine, S., Deneubourg, J.-L., Franks, N. R., Sneyd, J., Theraulaz, G., \& Bonabeau, E. (2001). Self-Organization in Biological Systems. Princeton: Princeton University Press.

Crutchfield, J. P., Farmer, D. J., Packard, N. H., \& Shaw, R. S. (1986). Chaos. Scientific American(12), 46-57.

Czayka, L. (1974). Systemwissenschaft. Eine kritische Darstellung mit Illustrationsbeispielen aus den Wirtschaftswissenschaften. Pullach bei München: UTB.

Dennett, D. C. (1987). The intentional stance. Cambridge, Mass.: MIT Press.

de Meer, H., \& Koppeb, C. (2005). Characterization of self-organization. In R. Steinmetz \& K. Wehrle (Eds.), P2P Systems and Applications (pp. 227-246). Berlin: Springer.

Dress, A., Hendrichs, H., \& Küppers, G. (Eds.). (1986). Selbstorganisation. Munich: Piper.

Eisert, J., \& Wilkens, M. (2005). Gott würfelt doch - Zufall lässt sich nicht auf Ignoranz reduzieren. Retrieved 18/1, 2006, from

http://www.uni-potsdam.de/portal/feb05/titel/gott.html. 
Engels, F. (1844). The Condition of the Working Class in England. Retrieved 11.4.2006, from http://www.marxists.org/archive/marx/works/1845/condition-working-class/index.htm.

Fellermann, H. (2003). Die Suche nach einem universellen Komplexitätsmaß. Retrieved 12/27/2005, 2005, from http://www.usf.uni-osnabrueck.de/usf/beitraege/texte/027hauptseminar2002.pdf.

Frege, G. (1983). Über Sinn und Bedeutung. In K. Berba \& L. Kreiser (Eds.), Logik-Texte: Kommentierte Auswahl zur Geschichte der modernen Logik (pp. 423-441). Darmstadt: Wissenschaftliche Buchgesellschaft.

Galistel, C. R. (1980). The organization of action: a new synthesis. Hillsdale, N.J.: Lawrence Erlbaum.

Gleick, J. (1987). Chaos - Making a New Science. Harmondsworth, Middlesex: Penguin Books Ltd.

Gregory, R. L., \& Zangwill, O. L. (Eds.). (1987). The Oxford Companion to the Mind. Oxford: Oxford University Press.

Gregory, R. L. (Ed.). (2004). The Oxford Companion to the Mind. Oxford: Oxford University Press.

Haken, H. (1978). Synergetics - an introduction. Berlin: Springer.

Haken, H. (1984). Erfolgsgeheimnisse der Natur: Synergetik: die Lehre vom Zusammenwirken. Frankfurt, M.; Berlin; Wien: Ullstein-Sachbuch.

Haken, H., \& Stadler, M. E. (Eds.). (1990). Synergetics of Cognition. Berlin: Springer.

Haken, H. (2005). Synergetics: from physics to economics. In K. Dopfer (Ed.), The evolutionary foundations of economics (pp. 70-85). Cambridge: Cambridge University Press.

Haugeland, J. (1981). Semantic engines: An introduction to mind design. In J. Haugeland (Ed.), Mind design (pp. 1-34). Cambridge, Mass.: MIT Press.

Hawking, S. (2005). Does God Play Dice? Retrieved 28.3.2006, from http://www.hawking.org.uk/pdf/dice.pdf.

Heisenberg, W. (1983). Quantentheorie und Philosophie (edited by Jürgen Büsche). Stuttgart: Philipp Reclam jun.

Hofstadter, D. R. (1999). Gödel, Escher, Bach: an eternal golden braid. New York: Basic Books.

Hofstadter, D. R., \& Dennett, D. C. (2000). The mind's I : fantasies and reflections on self and soul. New York: Basic Books. 
Johnson, S. (2001). Emergence - The connected live of ants, brains, cities and software. New York: Scribner.

Johnson, A. G. (2000). The Blackwell dictionary of sociology : a user's guide to sociological language. Oxford: Blackwell.

Jürgens, H., Peitgen, H.-O., \& Saupe, D. (1989). Fraktale - eine neue Sprache für komplexe Strukturen. Spektrum der Wissenschaft, 9, 52-64.

Kirman, A. (1998). Self-organization and evolution in economics. In F. Schweitzer \& G. Silverberg (Eds.), Selbstorganisation (pp. 13-45). Berlin: Duncker \& Humblot.

Köstler A. (1969). Beyond atomism and holism - the concept of the holon. In A. a. J. R. S. Koestler (Ed.), Beyond Reductionism: New Perspectives in the Life Sciences. The Alpabach Symposium (pp. 192-216). London: Hutchinson \& Co.

Klir, G. (1991). Facets of Systems Science. New York: Plenum Press.

Kriz, J. (1992). Chaos und Struktur. München: Quintessenz.

Krohn, W., Küppers, G., \& Paslack, R. (1987). Selbstorganisation - Zur Genese und Entwicklung einer wissenschaftlichen Revolution. In S. J. Schmidt (Ed.), Der Diskurs des radikalen Konstruktivismus (pp. 441-465). Frankfurt, M.: Suhrkamp.

Krohn, W., \& Küppers, G. (1992). Selbstorganisation. Zum Stand einer Theorie in den Wissenschaften. In G. Küppers \& W. Krohn (Eds.), Emergenz - Die Entstehung von Ordnung, Organisation und Bedeutung (pp. 7-26). Frankfurt, M.: Suhrkamp.

Krugman, P. (2004). How the economy organizes itself in space: a survey of the new economic geography. In J. B. Rosser (Ed.), Complexity in Economics (Vol. III, pp. 127-146). Cheltenham, UK: Edward Elgar Publ.

Küppers, G., \& Krohn, W. (Eds.). (1992). Emergenz - Die Entstehung von Ordnung, Organisation und Bedeutung. Frankfurt, M.: Suhrkamp.

Leven, R. W., Koch, B.-P., \& Pompe, B. (1989). Chaos in dissipativen Systemen. Berlin: Vieweg.

Liening, A. (1999). Komplexe Systeme zwischen Ordnung und Chaos. Münster: LIT Verlag.

Luhmann, N. (1984). Soziale Systeme. Frankfurt, M.: Suhrkamp.

Metzger, W. (1975). Gesetze des Sehens. Frankfurt, M.: Verlag Waldemar Kramer.

Metzler, W. (1987). Dynamische Systeme in der Ökologie. Stuttgart: Teubner. 
Miller, G. A., Galanter, E., \& Pribram, K. H. (1960). Plans and the Structure of Behavior. New York: Holt, Rinehart \& Winston.

Olson, M. (1965). The Logic of Collective Action. Public Goods and the Theory of Groups, Harvard University Press.

Ostrom, E. (2005). Understanding institutional diversity. Princeton: Princeton University Press.

Outhwaite, W. (Ed.). (1998). The Blackwell dictionary of twentieth-century social thought. Oxford: Blackwell.

Peitgen, H.-O., \& Richter, P. H. (1986). The beauty of fractals. Berlin: Springer.

Nicolis, G., \& Prigogine, I. (1987). Die Erforschung des Komplexen. München: Piper.

Prigogine, I. (1977). Time, Structure and Fluctuations - The Nobel Prize Lecture Chemistry. . Retrieved 04/23, 2006, from

http://nobelprize.org/chemistry/laureates/1977/prigogine-lecture.pdf.

Putnam, H. (1981). Reason, truth and history. Cambridge, Mass.: Cambridge University Press.

Putnam, H. (1991). Repräsentation und Realität. Frankfurt, M.: Suhrkamp.

Ros, A. (1990). Begründung und Begriff: Wandlungen desVerständnisses begrifflicher Argumentationen. Hamburg: Felix Meiner.

Ros, A. (1994). Bemerkungen zum Verhältnis zwischen Neurophysiologie und Psychologie. Saarbrücken.

Roth, G. (1980). Cognition as a self-organizing system. In F. Benseler, P.M. Hejl, W.K. Köck (Eds.), Autopoiesis, Communication and Society (45-52). Frankfurt, M.: Campus,.

Roth, G. (1987). Erkenntnis und Realität: Das reale Gehirn und seine Wirklichkeit. In S. J. Schmidt (Ed.), Der Diskurs des radikalen Konstruktivismus (pp. 229-255). Frankfurt, M.: Suhrkamp Taschenbuch Wissenschaft.

Schiemenz, B. (2000). Systemtheorie. In H. Corsten (Ed.), Lexikon der Betriebswirtschaftslehre (pp. 927). München: Oldenbourg.

Schuster, G. H. (1984). Deterministic chaos. Weinheim: Physik Verlag.

Schweitzer, F. (Ed.). (1997). Self-Organization of Complex Structures: From Individual to Collective Dynamics. London: Gordon and Breach.

Skirke, U. (2005). Technologie und Selbstorganisation -Zum Problem eines zukunftsfähigen Fortschrittsbegriffs. Retrieved 12/23, 2005, from http://www.on-line.de/ u.skirke/ tus_titel.html und http://www.on-line.de/ u.skirke/2_2.html. 
Suppes, P. \& Zinnes, J.L. (1963). Basic Measurement Theory. In: Luce, R.D., Bush, R. \& Galanter, E. (Eds.): Handbook of Mathematical Psychology Vol. I. (pp. 1 - 76). New York: Wiley.

Voigt, S. (2002). Institutionenökonomik. München: Wilhelm Fink (utb).

von Bertalanffy, K. L. (1949). Zu einer allgemeinen Systemlehre. Biologia Generalis, 19, 139164. (originally 1945 in Blätter für deutsche Philosophie, 3/4).

von Wright, G. H. (1971). Explanation and Understanding. New York: Cornell University Press.

Weiss, P. A. (1970). Das lebende System: Ein Beispiel für denSchichtendeterminismus. In A. Koestler \& J. R. Smythes (Eds.), Das neue Menschenbild. Die Revolutionierung der Wissenschaften vom Leben: Ein internationales Symposium (1968) (pp. 13-70). Wien: Verlag Fritz Molden.

Weiss, P. A. (1969). The Living System: Determinism Stratified. In A. Koestler, and J. R. Smythies, (Eds.), Beyond Reductionism: New Perspectives in the Life Sciences. (The Alpbach Symposium,) (pp. 3-55), New York: The Macmillan Co.

Weiss, P. A., et al. (1971). Hierarchically Organized Systems in Theory and Practice. New York: Hafner.

Wiener, N. (1948). Cybernetics. Cambridge, Mass.: M.I.T. Press.

Wiesendanger, H. (1987). Mit Leib und Seele - Ursprung, Entwicklung undAuflösung eines philosophischen Problems. Frankfurt, M.: Peter Lang. 